\title{
Impact of Solar Activity on Global Atmospheric Circulation Based on SD-WACCM-X Simulations from 2002 to 2019
}

\author{
Chen-Ke-Min Teng ${ }^{1} \mathbb{D}$, Sheng-Yang Gu ${ }^{1,2, *}$, Yusong Qin ${ }^{1} \mathbb{D}$ and Xiankang Dou ${ }^{1}$ \\ 1 Electronic Information School, Wuhan University, Wuhan 430072, China; tckm@whu.edu.cn (C.-K.-M.T.); \\ qinyusong@whu.edu.cn (Y.Q.); dou@ustc.edu.cn (X.D.) \\ 2 Key Laboratory of Geospace Environment, School of Earth and Space Sciences, Chinese Academy of Sciences, \\ University of Science \& Technology of China, Hefei 230027, China \\ * Correspondence: gushengyang@whu.edu.cn
}

Citation: Teng, C.-K.-M.; Gu, S.-Y.; Qin, Y.; Dou, X. Impact of Solar Activity on Global Atmospheric Circulation Based on SD-WACCM-X Simulations from 2002 to 2019.

Atmosphere 2021, 12, 1526.

https://doi.org/10.3390/

atmos12111526

Academic Editor: Maxim G. Ogurtsov

Received: 17 September 2021

Accepted: 16 November 2021

Published: 19 November 2021

Publisher's Note: MDPI stays neutral with regard to jurisdictional claims in published maps and institutional affiliations.

Copyright: (C) 2021 by the authors. Licensee MDPI, Basel, Switzerland. This article is an open access article distributed under the terms and conditions of the Creative Commons Attribution (CC BY) license (https:// creativecommons.org/licenses/by/ $4.0 /)$.

\begin{abstract}
In this study, a global atmospheric model, Specified Dynamics Whole Atmosphere Community Climate Model with thermosphere and ionosphere eXtension (SD-WACCM-X), and the residual circulation principle were used to study the global atmospheric circulation from the lower to upper atmosphere ( $500 \mathrm{~km})$ from 2002 to 2019 . Our analysis shows that the atmospheric circulation is clearly influenced by solar activity, especially in the upper atmosphere, which is mainly characterized by an enhanced atmospheric circulation in years with high solar activity. The atmospheric circulation in the upper atmosphere also exhibits an 11 year period, and its variation is highly correlated with the temporal variation in the F10.7 solar index during the same time series, with a maximum correlation coefficient of up to more than 0.9. In the middle and lower atmosphere, the impact of solar activity on the atmospheric circulation is not as obvious as in the upper atmosphere due to some atmospheric activities such as the Quasi-Biennial Oscillation (QBO), El Niño-Southern Oscillation (ENSO), sudden stratospheric warming (SSW), volcanic forcing, and so on. By comparing the atmospheric circulation in different latitudinal regions between years with high and low solar activity, we found the atmospheric circulation in mid- and high-latitude regions is more affected by solar activity than in low-latitude and equatorial regions. In addition, clear seasonal variation in atmospheric circulation was detected in the global atmosphere, excluding the regions near $10^{-4} \mathrm{hPa}$ and the lower atmosphere, which is mainly characterized by a flow from the summer hemisphere to the winter hemisphere. In the middle and low atmosphere, the atmospheric circulation shows a quasi-biennial oscillatory variation in the low-latitude and equatorial regions. This work provides a referable study of global atmospheric circulation and demonstrates the impacts of solar activity on global atmospheric circulation.
\end{abstract}

Keywords: SD-WACCM-X simulations; global atmospheric circulation; solar activity

\section{Introduction}

Atmospheric circulation is the state of widespread atmospheric motion. It includes the average state of atmospheric motion over a large area or a certain atmospheric layer over a long period of time or the process of atmospheric motion over a certain period of time [1]. It is a significant process in the global atmosphere, as it can transport and balance angular momentum, heat, and moisture in the Earth's atmospheric system, and mutually convert various energies [1-5]. It is also an important result of the transport, balance, and conversion of these physical quantities [6-8]. Therefore, studying the characteristics of atmospheric circulation (its formation, maintenance, changes, and effects) and understanding its evolution are indispensable and important parts of human understanding of nature, and it will be conducive to improving and increasing the accuracy of weather forecasting, exploring global climate change, and more effectively using climate resources.

There are many types of atmospheric circulations such as the Hadley circulation, the Brewer-Dobson circulation, and so on [5,9-11]. Many related studies have been conducted 
about the influences of these atmospheric circulations. Schneider and Bordoni [5] reported eddy-mediated regime transitions in the seasonal cycle of the Halley circulation and their implications for monsoon dynamics. Using the Coupled Model Intercomparison Project 5 (CMIP5) model, Hardiman et al. [12] studied the morphology of the Brewer-Dobson circulation and its response to climate change. In periods of Arctic warming and cooling, the mesoscale atmospheric circulation has a significant influence on Spitsbergen air temperature, and the frequency of warm circulation types was higher and that of cool circulation types was lower during the Early Twentieth-Century Arctic Warming (ETCAW) [13]. Noguchi et al. [14] found that the Brewer-Dobson circulation was enhanced and affected the Hadley circulation during the 2019 Antarctic Sudden Stratospheric Warming (SSW) event, and these two circulations impact the atmosphere in the lower stratosphere and upper troposphere. In addition, many types of atmospheric models can be used to study atmospheric circulations. More detailed information on these models can be found in Maher et al. [10] and the references therein.

Atmospheric circulation can be influenced by some atmospheric phenomena and solar activities. These atmospheric phenomena mainly include the Quasi-Biennial Oscillation (QBO), El Niño-Southern Oscillation (ENSO), SSW, volcanic forcing, and so on. The QBO is a 23-27 month oscillation of zonal wind that occurs in the tropical stratosphere. A theory suggested by Ruzmaikin et al. states that the QBO can cause secondary meridional circulation, which then impacts wave propagation in the middle and upper stratosphere [15]. White et al. [16] supported the QBO's ability causes a secondary meridional circulation in the subtropics and enhance the Brewer-Dobson circulation at mid-to-high latitudes, which induces anomalous poleward wave propagation and teleconnection between the $\mathrm{QBO}$ and the polar vortex. This theory has also been supported by Garfinkel et al. [17] and $\mathrm{Lu}$ et al. [18]. Abalos et al. [19] used three kinds of reanalysis data to show that the QBO provides important contributions to the Brewer-Dobson circulation. The ENSO is the warm phase of a recurring climate pattern including oceanic and atmospheric processes across the tropical Pacific, which has important impacts on the interannual variability in the climate system [20]. Many studies have been conducted about the impacts of the ENSO on atmospheric circulation. Calvo et al. [21] found that the atmospheric circulation is enhanced in the lowermost tropical stratosphere during ENSO events. Simpson et al. [22] studied the responses of atmospheric circulation in the lower stratosphere to the ENSO in December-March based on observations and simulations. The stratospheric circulations show increased upwelling in the tropical regions and downwelling in the mid-latitude regions, and the responses in the mid-latitude regions are larger in the northern hemisphere than in the southern hemisphere. SSW is a dramatic large-scale meteorological phenomenon occurring in the winter polar stratospheric region [23], and can cause altered atmospheric circulation. Gu et al. [24] found an altered middle atmospheric circulation caused by the changes in planetary and gravity waves forcing during the 2009 major SSW. Noguchi et al. [14] indicated that both the Hadley circulation and Brewer-Dobson circulation were influenced by the 2019 Antarctic SSW. In addition, greenhouse gases also can influence atmospheric circulation. Many studies indicate that increases in greenhouse gases can accelerate atmospheric circulation [25-28].

Solar activity is a general term for a variety of different phenomena, such as sunspots, solar wind, flares, corona and, so on, in the solar atmosphere, and is closely related to the generation, transmission, and dissipation of the solar magnetic field [29]. Solar activity is cyclical, the most obvious of which is the $\sim 11$ year cycle. Solar activity has a significant impact on the Earth's atmosphere. It not only affects the composition of the Earth's atmosphere, but also certain dynamic processes of the atmosphere [30-32]. Additionally, it can indirectly influence seismic, hydrological, and other aspects [33]. Thus, many studies have focused on predicting solar activity and its impact on the Earth's atmosphere [34-38]. Whether solar activity impacts atmospheric circulation is a hot topic in atmosphere research. Wilcox [39] conducted some investigations into the possible influence of solar activity on atmospheric circulation. Kodera and Kuroda [40] suggested that solar activity can change 
the balance between the dynamically and radiatively controlled states, which can influence stratopause circulation. Koval et al. [41] used a general atmospheric circulation model to demonstrate that changes in solar activity can modify the middle atmospheric circulation. Vasilyeva et al. [42] discussed the possible effects of solar activity on the tropospheric temperature regime based on the analysis of the tropospheric temperature regime in the northern and southern hemispheres in 1948-2006. Sfica et al. [43] analyzed the response of atmospheric circulation to the solar activity in the northern hemisphere and the Atlantic in 1948-2012. Based on the Canadian Middle Atmosphere Model (CMAM), Karlsson and Kuilman [44] investigated the influences of solar activity on middle atmospheric residual circulation close to the solstics. Salinas et al. [45] indicated that solar activity can affect the circulation in the lower thermosphere which can modulate the content of $\mathrm{CO}_{2}$ in the lower thermosphere. Rao et al. [46] studied the responses of the Brewer-Dobson circulation to the solar cycle and found that the Brewer-Dobson circulation in the lower stratosphere intensifies during solar minima.

In this work, the Specified Dynamics Whole Atmosphere Community Climate Model with thermosphere and ionosphere eXtension (SD-WACCM-X) was utilized, and the impact of solar activity on global atmospheric circulation was analyzed based on simulations from 2002 to 2019. Although many relevant studies have examined the impacts of solar activity on atmospheric circulation, these researchers mainly focused on some specific atmospheric circulations or atmospheric circulations in specific regions such as the Hadley circulation and the Brewer-Dobson circulation or atmospheric circulations in the middle and lower atmosphere. In our study, we investigated the differences in global atmospheric circulation, not only including the middle and lower atmosphere but also the upper atmosphere ranging to $\sim 500 \mathrm{~km}$ during years of different solar activities, which are reported for the first time. In addition, the SD-WACCM-X can be run under real atmospheric and solar activities and reflect real atmospheric states, which is described in detail in Section 2. The findings can help us to investigate the responses of atmospheric circulation in the upper atmosphere to atmospheric activities occurring in the middle and lower atmosphere, and to analyze the differences in the effects of solar and atmospheric activity on global atmospheric circulation. The findings also provide a reference for the extent of the impact of global atmospheric circulation on specific events under different future solar activities. The model and method are introduced in Section 2. The research results follow in Section 3, and Section 4 presents the discussion and conclusions.

\section{Model and Method}

\section{1. $S D-W A C C M-X$}

SD-WACCM-X is a specified dynamics mode of the Whole Atmosphere Community Climate Model with thermosphere and ionosphere eXtension (WACCM-X), which is a comprehensive atmospheric coupled numerical model developed by the National Center for Atmospheric Research (NCAR). The WACCM-X uses the NCAR Community Earth System Model (CESM) as a common numerical framework and spans a range of altitude from the Earth's surface to the upper atmosphere with a top boundary height ranging from 500 to $700 \mathrm{~km}$. In addition to the atmospheric component, components are provided for oceans, land, sea ice, and so on. Meehl et al. [47] indicated that the WACCM coupled to the ocean model can produce more realistic simulations of solar responses. In this work, the WACCM-X was run with the atmospheric component and coupled to the prescribed ocean model, land model, and so on to ensure that the atmospheric simulations are more accurate, especially at the interfaces with land, ocean, etc. The WACCM or WACCM-X self-generates the QBO and ENSO and has an expanded database of volcanic sulfate aerosols [48-50]; it can reproduce SSW events well [51]. For the WACCM-X version used in this work, the spectral solar irradiances were input to the radiative transfer calculations to represent the solar activity, which were specified from the model constructed by Lean et al. [50,52]. All irradiances were scaled by 0.9965 following the recommendation of the Stratospheric Processes and Their Role in Climate (SPARC) group; this scaling reflects the new and lower 
estimate of total solar irradiance (TSI) reported by the Total Irradiance Monitor (TIM) in NASA's Solar Radiation and Climate Experiment (SORCE) [50,53]. Thus, WACCM-X has been widely used in research about atmospheric circulation responses to atmospheric and solar activities. Calvo et al. [21] used the WACCM to study the atmospheric circulation in the lowermost tropical stratosphere during ENSO events. They also indicated that the results were in excellent agreement with other analyses of observations. Based on SD-WACCM simulations, Salinas et al. [45] identified the solar cycle response of $\mathrm{CO}_{2}$ in the lower thermosphere via modulations of the circulation in the lower thermosphere. This discovery was also demonstrated using the satellite observations. In comparison, the SDWACCM provides more years of simulations to further validate the relevant conclusions. Using different reanalysis data and WACCM simulations, Rao et al. [46] studied the evaluation of the Brewer-Dobson circulation and its responses to the ENSO, the QBO, and the solar cycle. The WACCM simulations and those reanalysis data showed similar responses of the Brewer-Dobson circulation to the ENSO, the QBO, and the solar cycle. In addition, we conducted other atmospheric studies based on the SD-WACCM-X simulations and compared these results to others based on some observations [54,55]. Therefore, we think the SD-WACCM-X simulations in this work have high reliability and credibility. For more detailed information about WACCM-X, the reader is referred to Liu et al. [56] and Liu et al. [57] and the references therein. Marsh [58] also described the initial concepts and configurations of SD-WACCM-X. The official website of WACCM-X provides its overview and its download and installation procedures.

In this work, the range of SD-WACCM-X from the bottom boundary to $0.01 \mathrm{hPa}$ was constrained by the Modern-Era Retrospective Analysis for Research and Applications, Version 2 (MERRA-2) data. The MERRA-2 data are an atmospheric reanalysis dataset, incorporating various types of satellite observations, ground-based measurements, and the Goddard Earth Observing System (GEOS) model, produced by NASA's Global Modeling and Assimilation Office (GMAO) [59]. The MERRA-2 data mainly include wind, temperature, and ozone and water vapor contents data. Thus, the simulations constrained by MERRA-2 reanalysis data more accurately and credibly reflect the atmospheric statuses. In this work, the simulations were output once per hour with a horizontal resolution of $1.9^{\circ} \times 2.5^{\circ}$ (latitude $\times$ longitude). For the vertical resolution, the simulation results were divided into 145 layers.

\subsection{Method}

In this study, the residual circulation was applied to represent the global atmospheric circulation, which can be calculated as follows [23]:

$$
\begin{gathered}
v^{*}=\bar{v}-\rho^{-1}\left(\rho \overline{v^{\prime} \theta^{\prime}} / \overline{\theta_{z}}\right)_{z} \\
w^{*}=\bar{w}+(a \cos \varphi)^{-1}\left(\cos \varphi \overline{v^{\prime} \theta^{\prime}} / \overline{\theta_{z}}\right)_{\varphi}
\end{gathered}
$$

where $v$ and $w$ represent the meridional and vertical wind, respectively; a is the Earth's radius; $\rho$ is neutral air density; $\varphi$ is the latitude in radians; $\theta$ is the potential temperature; the horizontal line on the parameter represents the corresponding zonal mean value; the apostrophe represents the corresponding deviations from the zonal mean value; and the subscripts $z$ and $\varphi$ indicate the vertical and latitudinal gradients, respectively. Based on the residual circulation equations and SD-WACCM-X simulations, we obtained the atmospheric circulations of the global atmosphere from 2002 to 2019.

\section{Results}

Figure 1 shows the temporal variations in the F10.7 solar flux index from 2002 to 2019: the F10.7 solar indices in 2002, 2003, 2004, 2011, 2012, 2013, 2014, and 2015 are above 120, with the largest value in 2002. Thus, we define these years as having high solar activity with the strongest solar activity in 2002. The other years are considered to have 
low solar activity. Based on the SD-WACCM-X simulations and the residual circulation methodology described before, we calculated the global atmospheric circulation from 2002 to 2019. When analyzing the results of global atmospheric circulation, we found that the value of the vertical circulation was too small compared to the meridional circulation. To more accurately represent the characteristics of atmospheric circulation, we artificially multiplied the value of the vertical circulation by 10 in some subsequent plots and mark it on the corresponding chart.

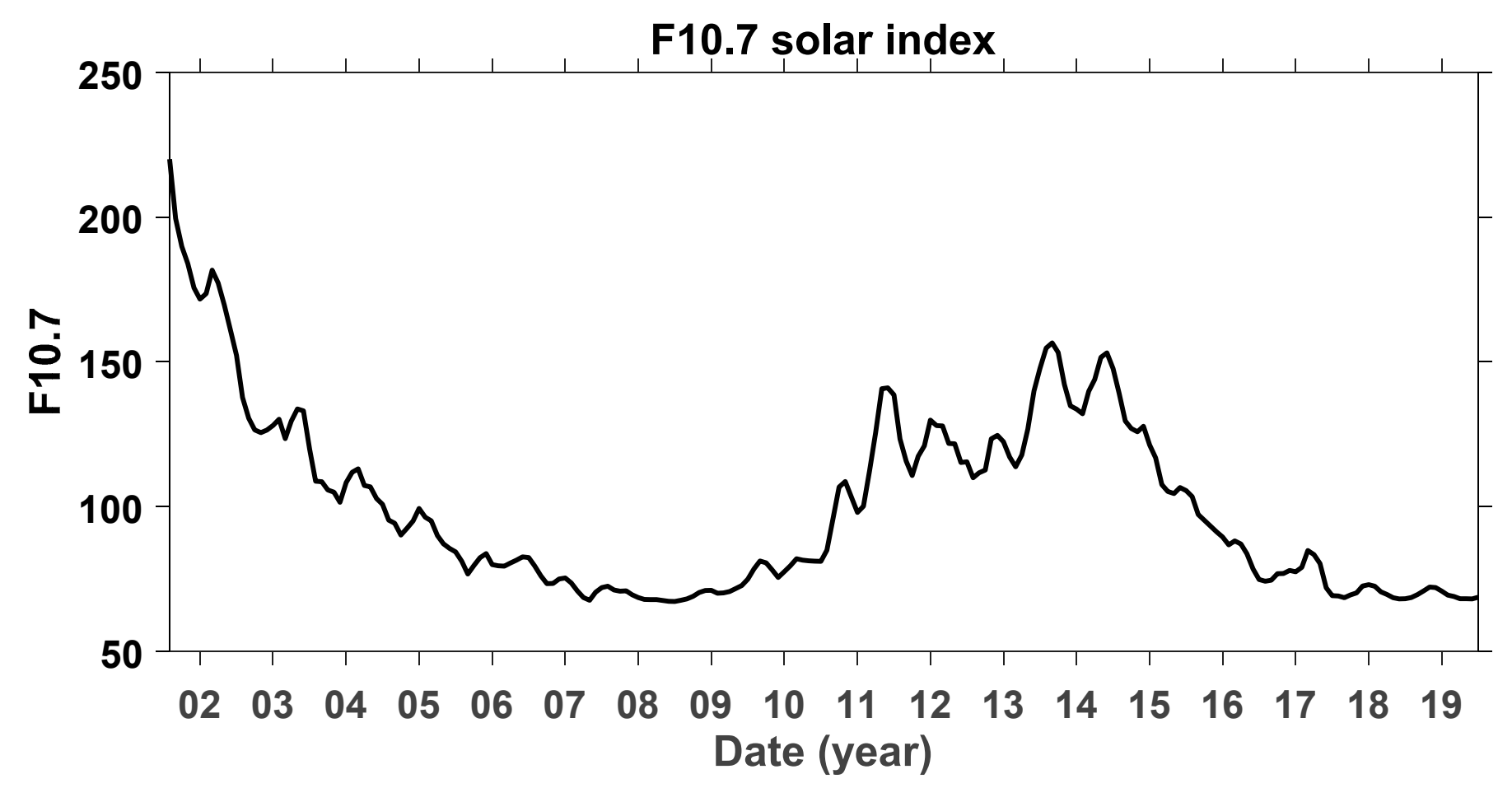

Figure 1. Temporal variations in the F10.7 solar index from 2002 to 2019.

Figures 2 and 3 show the temporal variations in the meridional and vertical circulation at different latitudinal regions. Clear seasonal variations in the meridional and vertical circulation are shown in the global atmosphere, excluding the regions near $10^{-4} \mathrm{hPa}$ and the lower atmosphere. The meridional circulation is mainly characterized by a flow from the summer hemisphere to the winter hemisphere. The vertical circulation shows a rise in the summer hemisphere and a fall in the winter hemisphere in mid- and high-latitude regions. However, in low-latitude and equatorial regions, the vertical circulation shows a fall in the summer hemisphere and a rise in the winter hemisphere, which is opposite to that in midand high-latitude regions. The amplitudes of meridional circulation at the same moment do not differ much in different latitude regions, whereas the vertical circulation shows highest and lowest intensity in high- and low-latitude regions, respectively. In addition, both intensities of the meridional and vertical circulation in the upper atmosphere are higher in years with high solar activity than in years with low solar activity, with the highest intensity in 2002. The temporal variations in the meridional and vertical circulation at different latitudinal regions are shown in Figure 4. The meridional and vertical circulations at $\sim 50$ and $\sim 90 \mathrm{~km}$ show local maximum amplitudes in mid- and low-latitude and equatorial regions. They do not exhibit stronger intensity during the years with high solar activity but instead show quasi-biennial variations in low-latitude and equatorial regions. The vertical circulation at $\sim 90 \mathrm{~km}$ shows the most obvious quasi-biennial oscillation. At $\sim 130$ and $\sim 170 \mathrm{~km}$, the local maximum amplitudes of meridional and vertical circulations are mainly observed in mid- and high-latitude regions. These local maximum meridional and vertical circulations are clearly enhanced during those years with high solar activity. In mid- and low-latitude regions, these meridional and vertical circulations show almost identical intensities during different solar activities. 
(a) Meridional Circulation at $\sim 70^{\circ} \mathrm{N}$

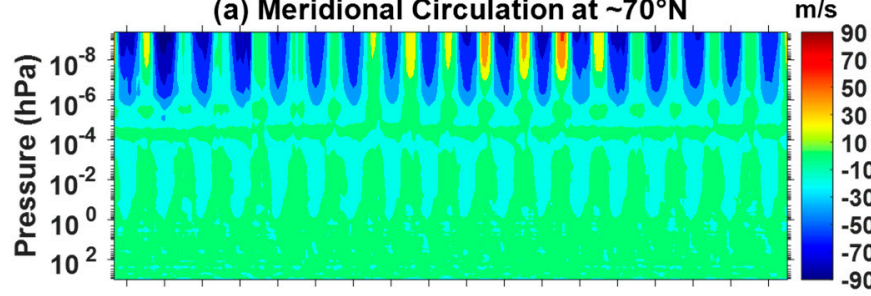

020304050607080910111213141516171819

(c) Meridional Circulation at $\sim 40^{\circ} \mathrm{N}$

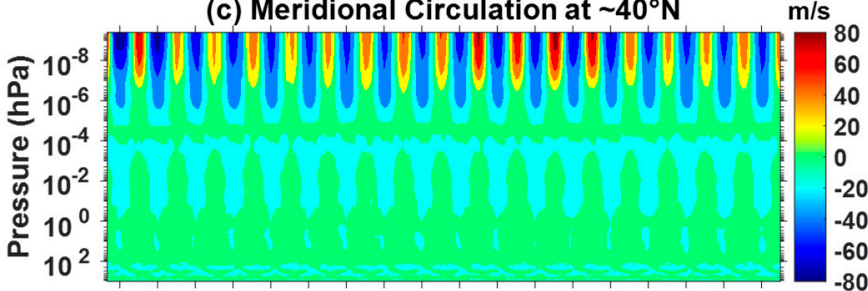

020304050607080910111213141516171819

(e) Meridional Circulation at $\sim 10^{\circ} \mathrm{N}$

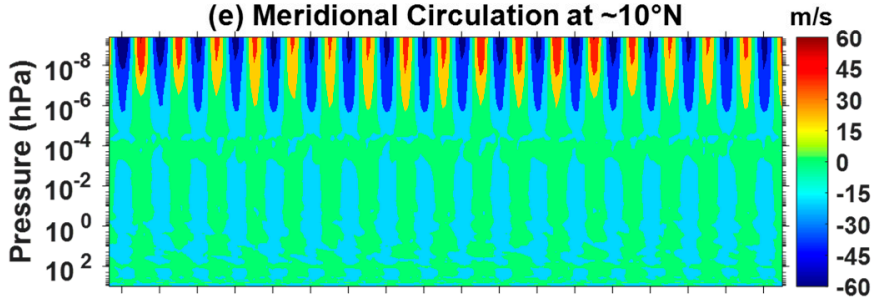

020304050607080910111213141516171819 Date (year) (b) Vertical Circulation at $\sim 70^{\circ} \mathrm{N}$

$\mathrm{m} / \mathrm{s} \times 0.1$

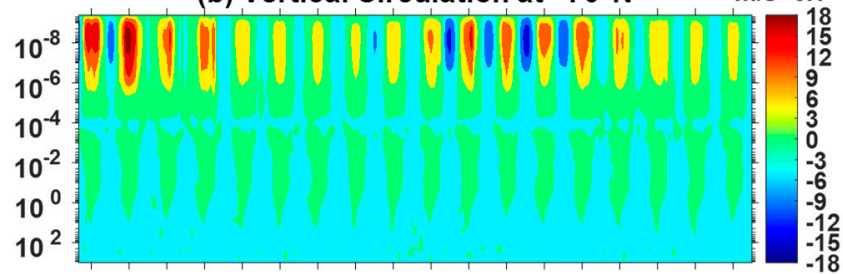

020304050607080910111213141516171819

(d) Vertical Circulation at $\sim 40^{\circ} \mathrm{N}$

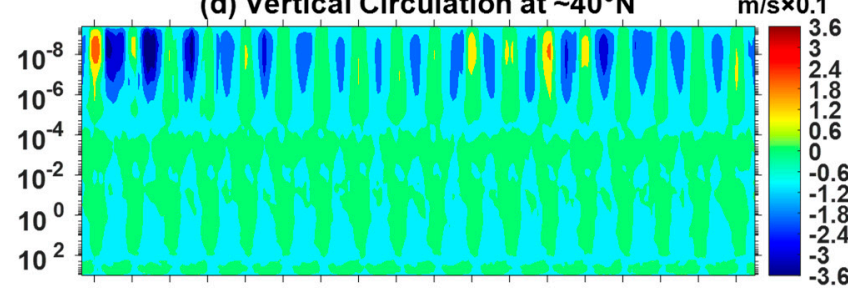

020304050607080910111213141516171819

(f) Vertical Circulation at $\sim 10^{\circ} \mathrm{N}$ $\mathrm{m} / \mathrm{s} \times 0.1$

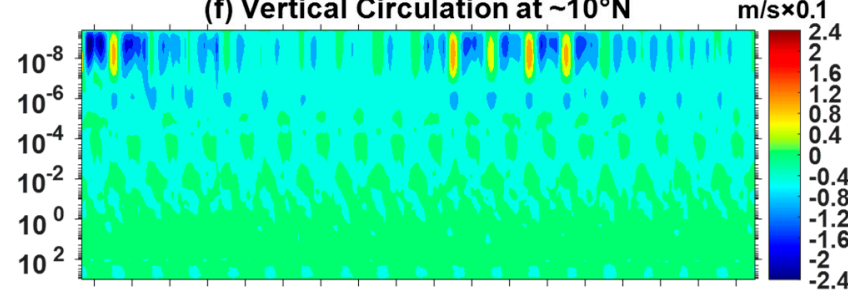

020304050607080910111213141516171819 Date (year)

Figure 2. Temporal variations in the $(\mathbf{a}, \mathbf{c}, \mathbf{e})$ meridional circulation and $(\mathbf{b}, \mathbf{d}, \mathbf{f})$ vertical circulation at $(\mathbf{a}, \mathbf{b}) \sim 70^{\circ} \mathrm{N},(\mathbf{c}, \mathbf{d})$ $\sim 40^{\circ} \mathrm{N}$, and $(\mathbf{e}, \mathbf{f}) \sim 10^{\circ} \mathrm{N}$ from 2002 to 2019.

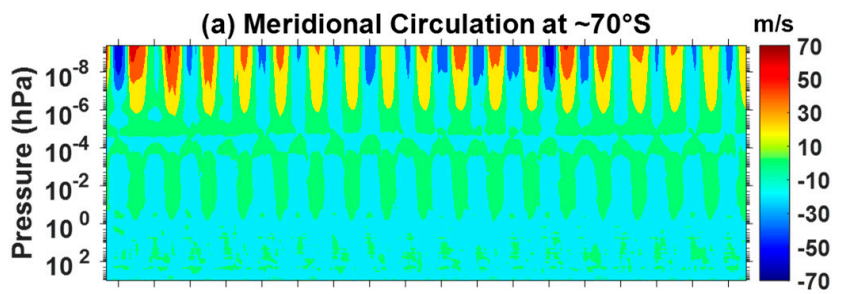

020304050607080910111213141516171819

(c) Meridional Circulation at $\sim 40^{\circ} \mathrm{S}$

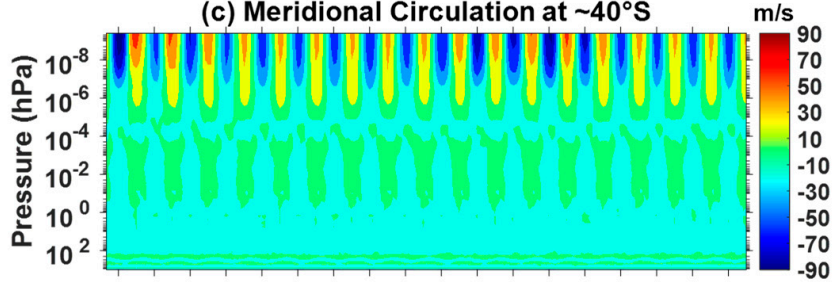

020304050607080910111213141516171819

(e) Meridional Circulation at $\sim 10^{\circ} \mathrm{S}$

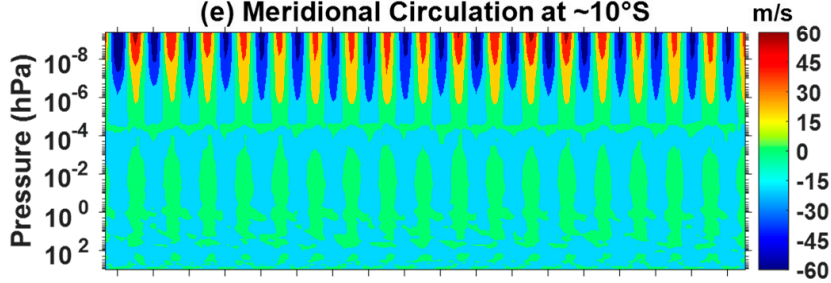

020304050607080910111213141516171819 Date (year) (b) Vertical Circulation at $\sim 70^{\circ} \mathrm{S}$

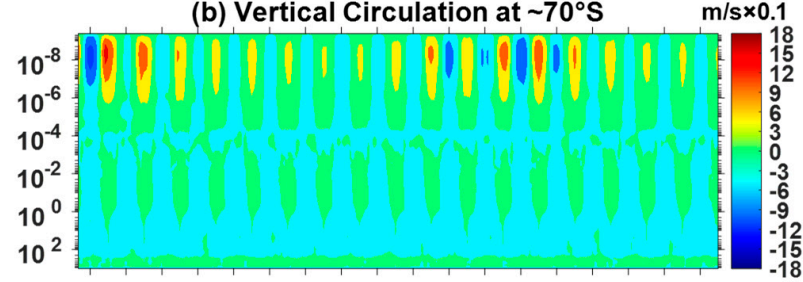

020304050607080910111213141516171819

(d) Vertical Circulation at $\sim 40^{\circ} \mathrm{S}$

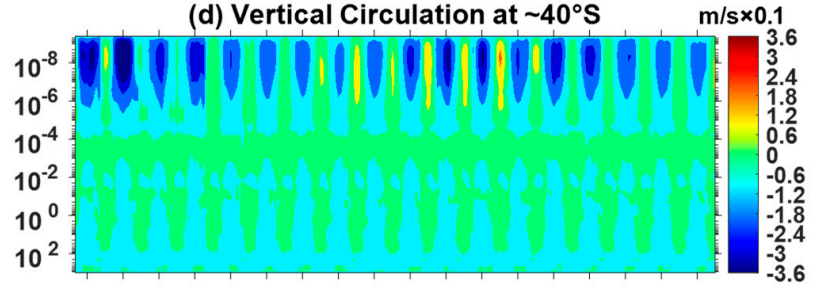

020304050607080910111213141516171819

(f) Vertical Circulation at $\sim 10^{\circ} \mathrm{S}$

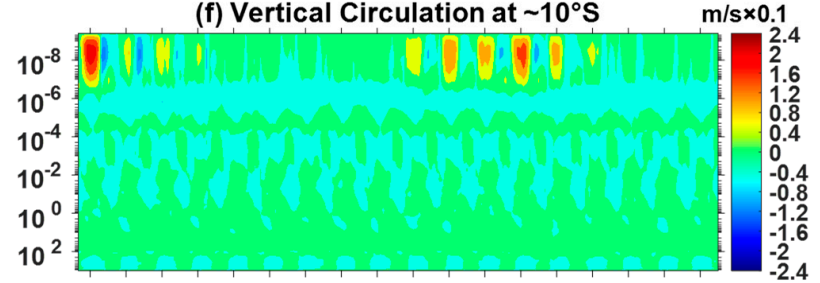

020304050607080910111213141516171819 Date (year)

Figure 3. Temporal variations in the $(\mathbf{a}, \mathbf{c}, \mathbf{e})$ meridional circulation and $(\mathbf{b}, \mathbf{d}, \mathbf{f})$ vertical circulation at $(\mathbf{a}, \mathbf{b}) \sim 70^{\circ} \mathrm{S},(\mathbf{c}, \mathbf{d}) \sim 40^{\circ} \mathrm{S}$, and $(\mathbf{e}, \mathbf{f}) \sim 10^{\circ} \mathrm{S}$. 


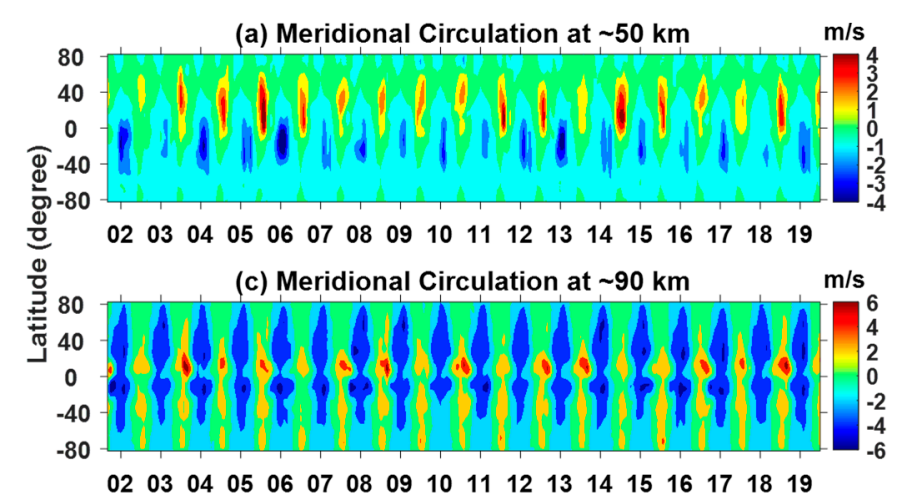

(e) Meridional Circulation at $\sim 130 \mathrm{~km}$

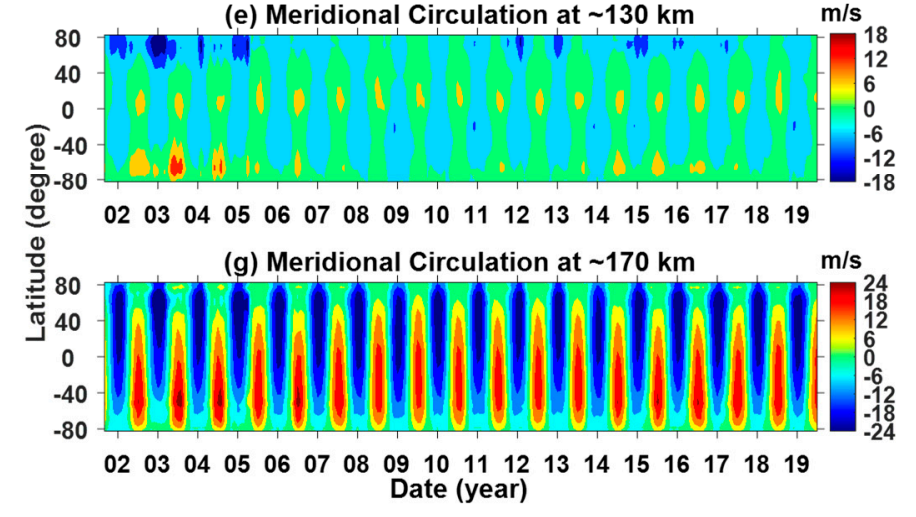

(b) Vertical Circulation at $\sim \mathbf{5 0} \mathbf{~ k m}$

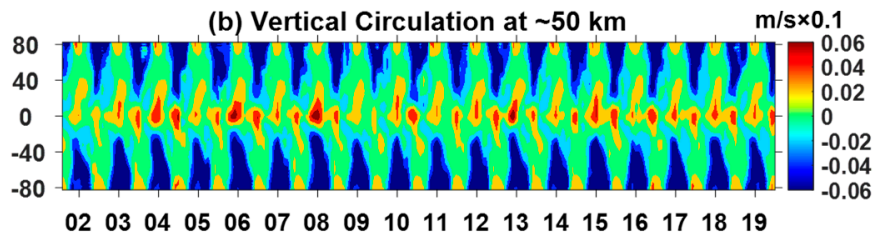

(d) Vertical Circulation at $\sim 90 \mathrm{~km}$

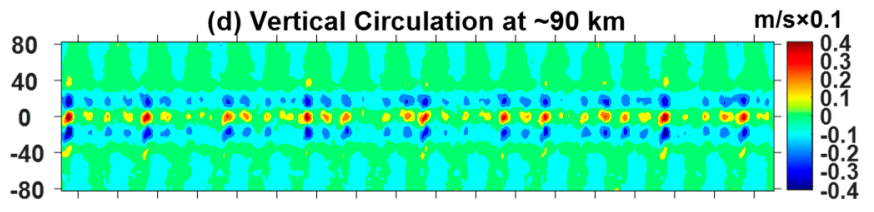

$\begin{array}{llllllllllllllllll}02 & 03 & 04 & 05 & 06 & 07 & 08 & 09 & 10 & 11 & 12 & 13 & 14 & 15 & 16 & 17 & 18 & 19\end{array}$

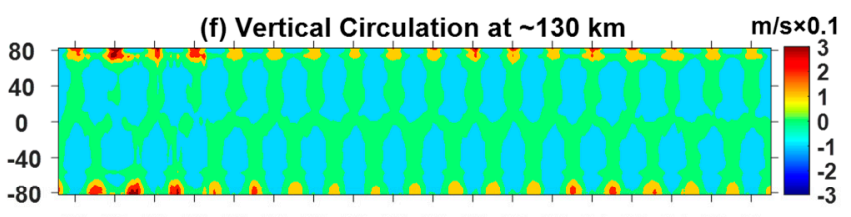

$\begin{array}{llllllllllllllllll}02 & 03 & 04 & 05 & 06 & 07 & 08 & 09 & 10 & 11 & 12 & 13 & 14 & 15 & 16 & 17 & 18 & 19\end{array}$

(h) Vertical Circulation at $\sim 170 \mathrm{~km}$

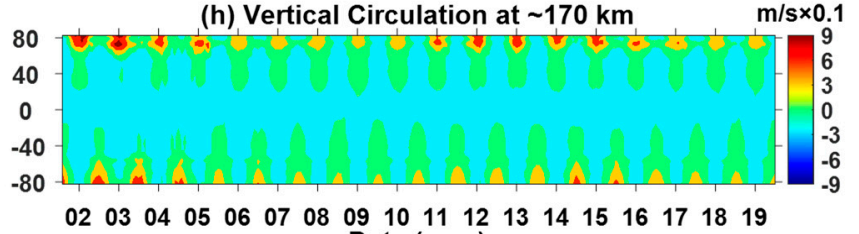

$\begin{array}{llllllllllllllllll}02 & 03 & 04 & 05 & 06 & 07 & 08 & 09 & 10 & 11 & 12 & 13 & 14 & 15 & 16 & 17 & 18 & 19\end{array}$

Figure 4. Temporal variations in the (a,c,e,g) meridional circulation and $(\mathbf{b}, \mathbf{d}, \mathbf{f}, \mathbf{h})$ vertical circulation at $(\mathbf{a}, \mathbf{b}) \sim 50 \mathrm{~km},(\mathbf{c}, \mathbf{d})$ $\sim 90 \mathrm{~km},(\mathbf{e}, \mathbf{f}) \sim 130 \mathrm{~km}$, and (g,h) $170 \mathrm{~km}$ from 2002 to 2019.

Figure 1 shows that the solar activity was strong in 2002 and weak in 2009. Thus, we chose simulations in these two years to investigate the details of the atmospheric circulation in years with high and low activity, respectively, and the differences in the atmospheric circulations in years with different solar activity intensities. Figure $5 a-d$ shows the temporal variations in the meridional and vertical circulations at $\sim 70^{\circ} \mathrm{S}$ in 2002 and 2009. The meridional circulation shows a flow toward the southern and northern pole in the winter and summer of the southern hemisphere, respectively. Vertical circulation shows downward and upward motion in the winter and summer of the southern hemisphere, respectively. These seasonal variations in the atmospheric circulation are particularly obvious in the upper atmosphere. It can also be seen that both meridional and vertical circulations in 2002 were stronger than in 2009, especially in the upper atmosphere. In order to more intuitively demonstrate these differences, we subtracted the results in 2002 from those in 2009; the differences are shown in Figure 5e,f. Figure 5e,f show that the motions of both the meridional and vertical circulations were stronger in 2002. However, in the middle and lower atmosphere, there was no significant difference between the atmospheric circulation in 2002 and 2009. The maximum differences in the meridional and vertical circulation were $\sim 40$ and $\sim 1 \mathrm{~m} / \mathrm{s}$, respectively. Considering the maximum amplitudes of the meridional and vertical circulation in 2002 were $\sim 70$ and $\sim 1.8 \mathrm{~m} / \mathrm{s}$, respectively, the difference between these two years is thought to be considerable. We also analyzed the atmospheric circulations at $\sim 10^{-8} \mathrm{hPa}$ in 2002 and 2009 and their differences, and these results are shown in Figure 6. The meridional circulations showed an obvious flow from the summer to winter hemisphere in 2002 and 2009 and the highest intensities in mid-latitude regions. The differences in the meridional circulation, shown in Figure 6e, indicate that the intensities of the meridional circulations in 2002 were higher than in 2009. These differences were mainly exhibited in mid- and high-latitude regions. The vertical circulation showed an obvious rise and fall motion in mid- and high-latitude regions of the summer and winter hemisphere, respectively. We identified an anomaly in the vertical circulation in low-latitude and equatorial regions compared to the mid- and high-latitude 
regions, which is also shown in Figures 2 and 3. The differences in Figure $6 \mathrm{f}$ show that the vertical circulation in 2002 was stronger, especially in mid- and high-latitude regions, than in 2009. Thus, this shows that the atmospheric circulation in 2002 was stronger than in 2009 and the differences were more obvious in mid- and high-latitude regions.
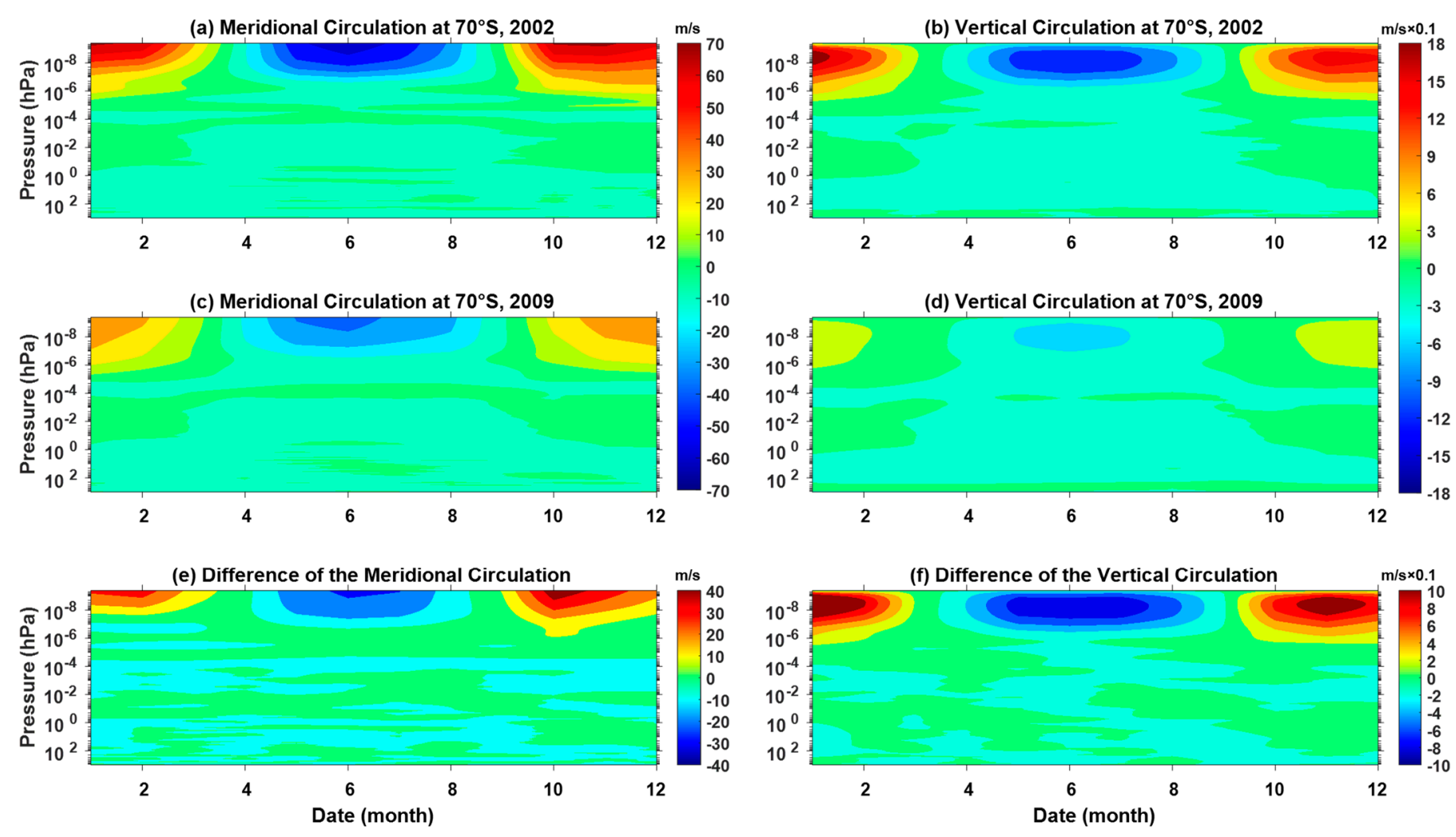

Figure 5. Temporal variations in the (a,c) meridional circulation and (b,d) vertical circulation at $\sim 70^{\circ} \mathrm{S}$ in $(\mathbf{a}, \mathbf{b}) 2002$ and (c,d) 2009. (e,f) Differences in the meridional and vertical circulation, respectively.

Based on the above results, the direction of the atmospheric circulation is different in summer and winter. Thus, we chose the atmospheric circulation in June and December to conduct further studies. The total atmospheric circulations in June 2002 and 2009 are shown in Figure 7a,c: the total atmospheric circulation was upward and downward in the high-latitude regions of the northern and southern hemisphere, respectively, and there was obvious pole-to-pole circulation from the northern to the southern hemisphere. Again, we subtracted the total atmospheric circulations in June 2002 from those in June 2009, as shown in Figure 7e. The differences in the total atmospheric circulations also showed an obvious pole-to-pole flow from the northern to the southern hemisphere and a rise and fall flow in the high-latitude regions of the northern and southern hemisphere, respectively. In the upper atmosphere, the differences were obvious at mid- and high-latitude regions, and the differences were weaker in low-latitude and equatorial regions. Due to the lower intensities of the atmospheric circulations in the middle and lower atmosphere than in the upper atmosphere, the total atmospheric circulations in the middle and lower atmosphere are shown separately in Figure $7 \mathrm{~b}, \mathrm{~d}$,f. Excluding the regions near $10^{-4} \mathrm{hPa}$, the pole-to-pole circulations from the northern to the southern hemisphere were obvious in June 2002 and 2009. The differences in the total atmospheric circulations do not show the same pole-topole flow exhibited in Figure $7 \mathrm{~b}, \mathrm{~d}$, and the flow directions are different in the different regions. This indicates that the total atmospheric circulations in the middle and lower atmosphere in June 2002 were not always stronger than those in June 2009. The same as in Figure 7, Figure 8 shows the total atmospheric circulations in December 2002 and 2009 and the differences between them. Excluding the regions near $10^{-4} \mathrm{hPa}$, the total atmospheric circulations showed a pole-to-pole flow from the southern to the northern 
hemisphere and a rise and fall flow at flow in the high-latitude regions of the southern and northern hemisphere, respectively. The differences in the atmospheric circulations in the upper atmosphere show the same flow directions as in Figure 8a,c, especially in the mid- and high-latitude regions, which indicates the atmospheric circulations in the upper atmosphere were stronger in December 2002. The differences in the middle and lower atmosphere also show different flow directions in the different regions, which indicates the atmospheric circulations in the middle and lower atmosphere in December 2002 were not always stronger than in December 2009. Figures 7 and 8 demonstrate that the flow direction of the atmospheric circulations is from the summer hemisphere to the winter hemisphere, and the total atmospheric circulations in the upper atmosphere are stronger in years with high solar activity.

(a) Meridional Circulation at $\sim 10^{-8} \mathrm{hPa}, 2002$

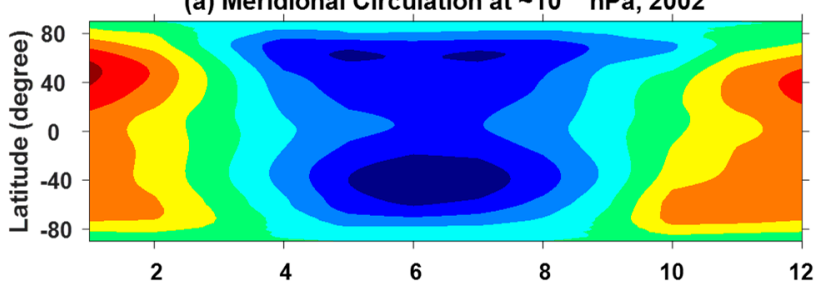

(c) Meridional Circulation at $\sim 10^{-8} \mathrm{hPa}, 2009$

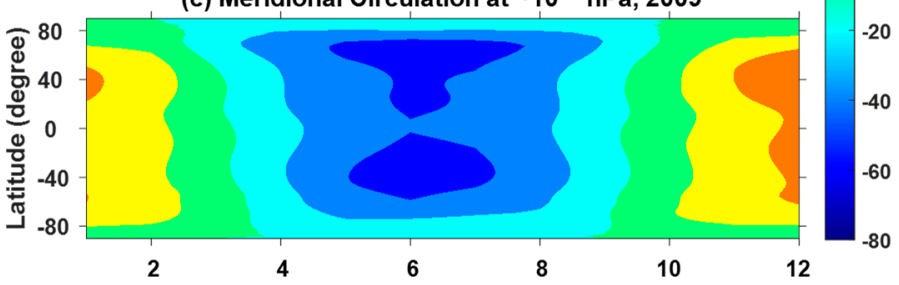

(e) Difference of the Meridional Circulation

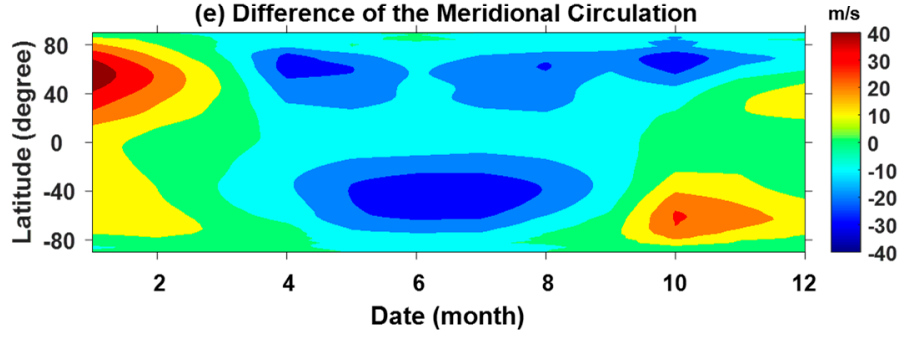

(b) Vertical Circulation at $\sim 10^{-8} \mathrm{hPa}, 2002$

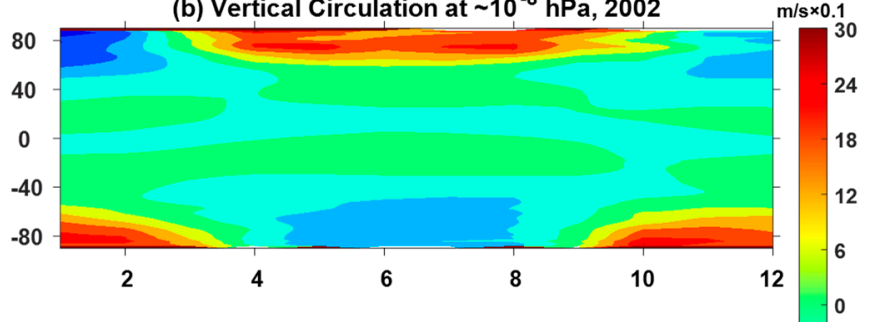

(d) Vertical Circulation at $\sim 10^{-8} \mathrm{hPa}, 2009$
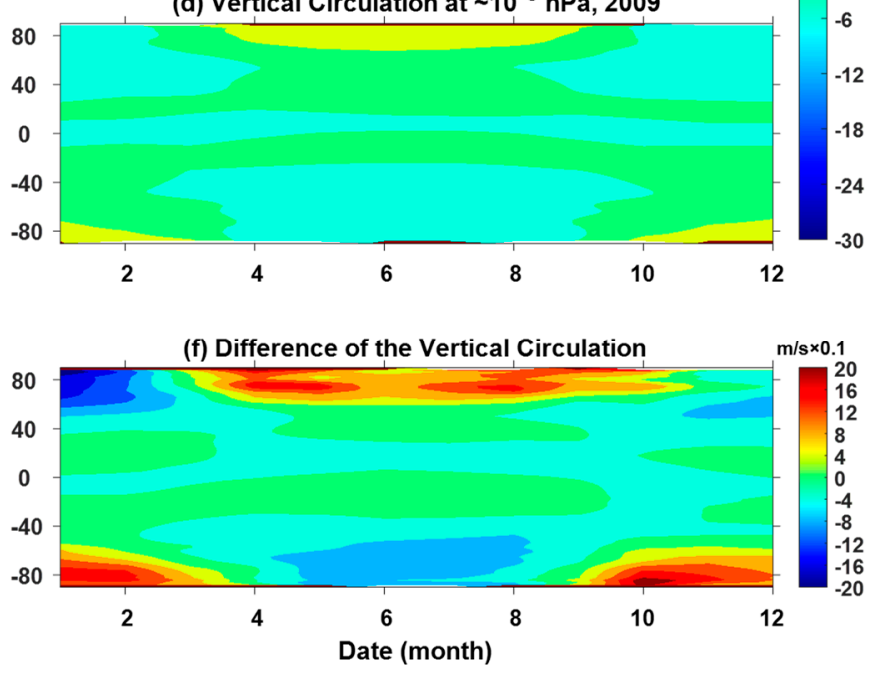

Figure 6. Temporal variations in the (a,c) meridional circulation and (b,d) vertical circulation at $\sim 10^{-8} \mathrm{hPa}$ in $(\mathbf{a}, \mathbf{b}) 2002$ and (c,d) 2009. (e,f) Differences in the meridional and vertical circulation, respectively.

We also analyzed the temporal variations in the meridional and vertical components of atmospheric circulation at a specified altitude and latitude, and compared these results to the F10.7 solar index during the same time series. From the results above, we know that the meridional and vertical circulations show consistent variations in the northern and southern hemispheres. Thus, we only show these temporal variations in the atmospheric circulation and comparisons at the specified latitude in the southern hemisphere; the values of atmospheric circulations are reported in magnitude only without regard to direction. Figures 9 and 10 show these temporal variations in the atmospheric circulation and comparisons in June and December, respectively. Both meridional and vertical circulations at $\sim 10^{-8} \mathrm{hPa}$ show almost consistent variations with the F10.7 solar index during the same time series. Rare differences can be identified in the comparisons. For example, the meridional circulation in June at $\sim 10^{-8} \mathrm{hPa}$ and $\sim 70^{\circ} \mathrm{S}$ showed inconsistent variations with the F10.7 solar index from 2002 to 2009 . At $\sim 10^{-4}$ and $\sim 10^{-2} \mathrm{hPa}$, no consistent variations can be observed between the temporal variations in the atmospheric circulation and the F10.7 solar index during the same time series. It seems, however, that these two variations in the corresponding component of the atmospheric circulation 
and the F10.7 solar index show consistency in years with high solar activity. In order to more visually demonstrate the correlation between the variations in the meridional and vertical circulation and the F10.7 solar index during the same time series, we calculated the correlation coefficients of these corresponding parameters, as shown in Table 1 . The correlation coefficients at $\sim 10^{-8} \mathrm{hPa}$ are high with the highest coefficient of 0.9459 ; there are also a few low correlation coefficients such as 0.1578 and 0.1907 . However, from an overall global atmospheric perspective, the variations in the atmospheric circulation in the upper atmosphere are consistent with the corresponding variations in the F10.7 solar index during the same time series. Table 1 also exhibits the low correlation coefficients at $\sim 10^{-4}$ and $\sim 10^{-2} \mathrm{hPa}$, with some negative correlation coefficients. This indicates that the temporal variations in the atmospheric circulation in the middle and low atmosphere are inconsistent with the variations in the F10.7 solar index during the same time series. The errors of these correlation coefficients are mostly about 0.1 , within $95 \%$ confidence intervals, which indicates the high credibility of these correlation coefficients. We also performed a spectral analysis of the meridional and vertical circulations over these years, as shown in Figures 11 and 12, respectively. For the meridional circulation at $\sim 10^{-8} \mathrm{hPa}$, an obvious $\sim 11$ year period is shown in mid- and high-latitude regions, and the $\sim 11$ year period in June and December is more obvious in the southern and northern hemisphere, respectively. However, no $\sim 11$ year period appears in low-latitude regions. Thus, we show the spectra only at low latitude regions. An $\sim 11$ year period was identified in low-latitude regions but with less power than in mid- and high-latitude regions. At $\sim 10^{-4}$ and $\sim 10^{-2} \mathrm{hPa}$, no obvious $\sim 11$ year period can be observed; instead, an $\sim 16$ year period is exhibited. For vertical circulation, an obvious $\sim 11$ year period occurs at $\sim 10^{-8} \mathrm{hPa}$ but not at $\sim 10^{-4}$ or $\sim 10^{-2} \mathrm{hPa}$, which is consistent with the periods for the meridional circulation.

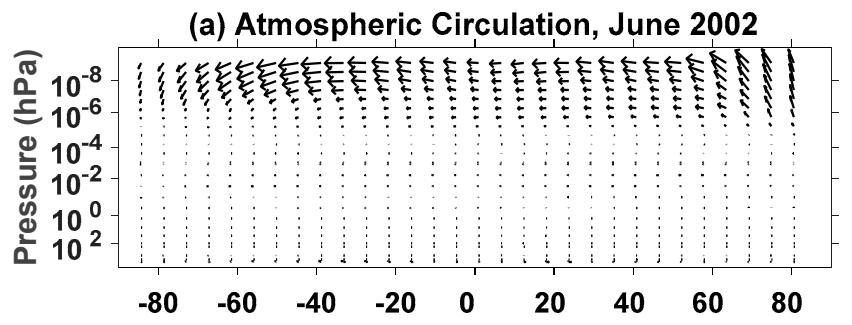

(c) Atmospheric Circulation, June 2009

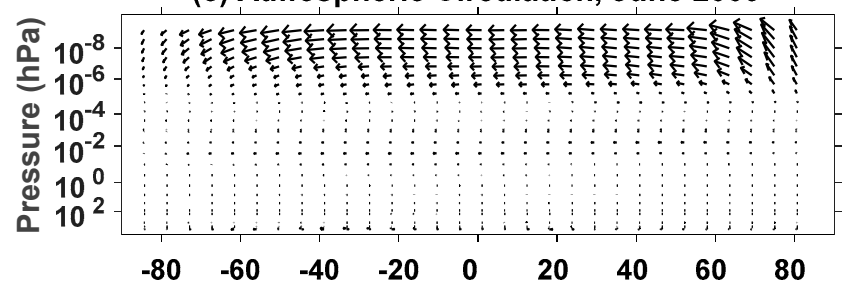

(e) Difference of the Atmospheric Circulation

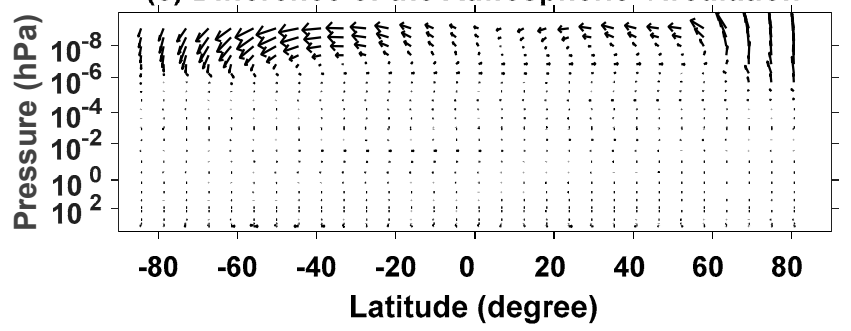

(b) Atmospheric Circulation, June 2002

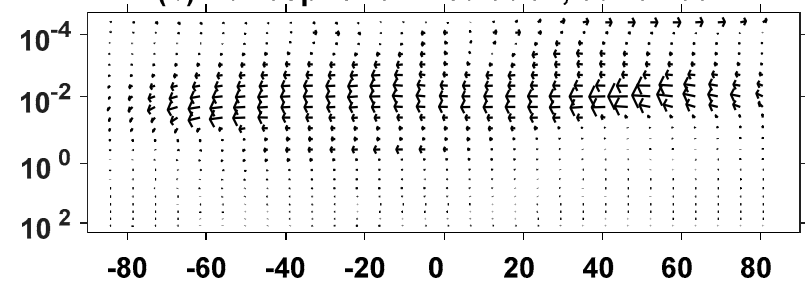

(d) Atmospheric Circulation, June 2009

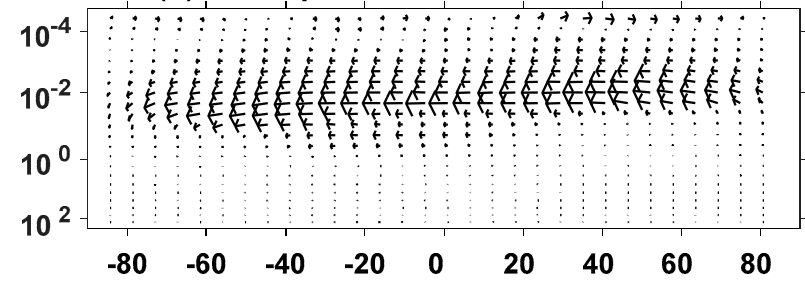

(f) Difference of the Atmospheric Circulation

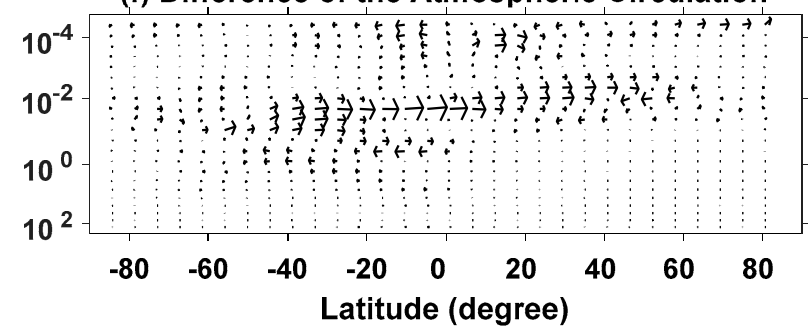

Figure 7. Atmospheric circulation in June (a,b) 2002 and (c,d) 2009. (e,f) Differences in the atmospheric circulation in June between 2002 and 2009. Left and right panels show the atmospheric circulation in the global atmosphere and in the middle and lower atmosphere, respectively. 
(a) Atmospheric Circulation, December 2002

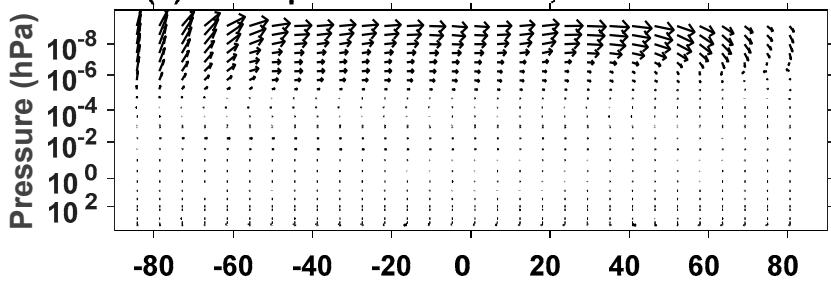

(c) Atmospheric Circulation, December 2009

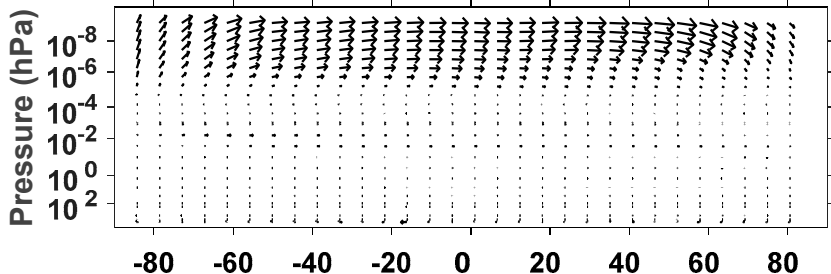

(e) Difference of the Atmospheric Circulation

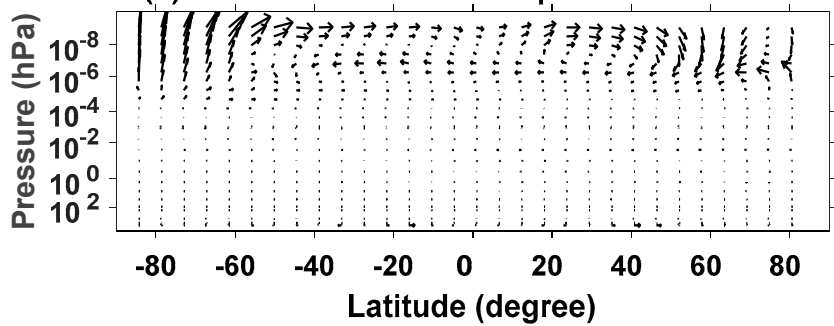

(b) Atmospheric Circulation, December 2002

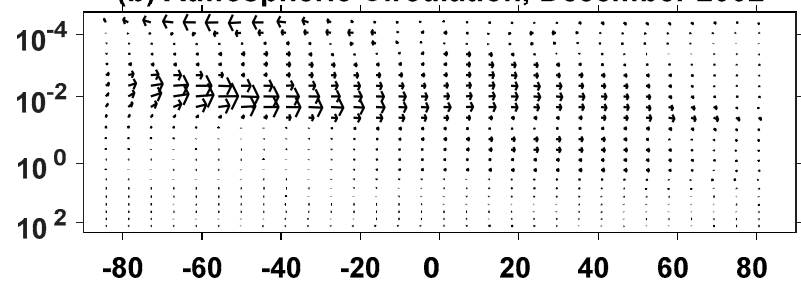

(d) Atmospheric Circulation, December 2009

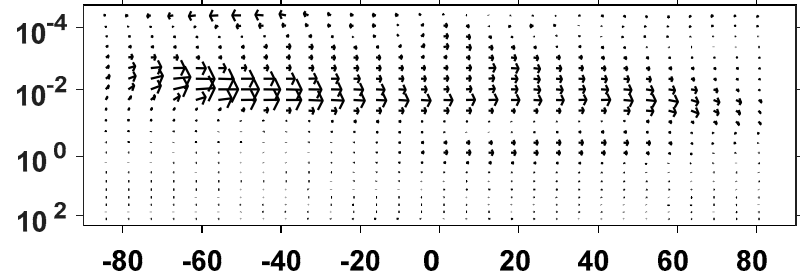

(f) Difference of the Atmospheric Circulation

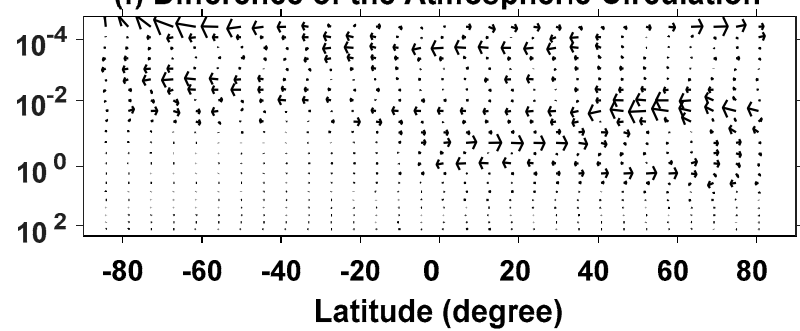

Figure 8. Atmospheric circulation in December (a,b) 2002 and (c,d) 2009. (e,f) Differences in the atmospheric circulation in December between 2002 and 2009. Left and right panels show the atmospheric circulation in the global atmosphere and in the middle and lower atmosphere, respectively.
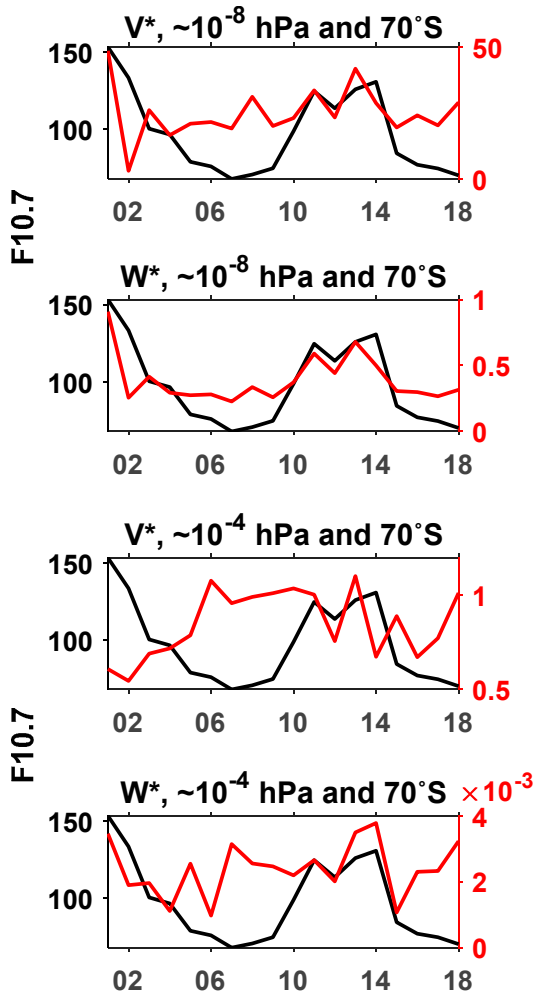
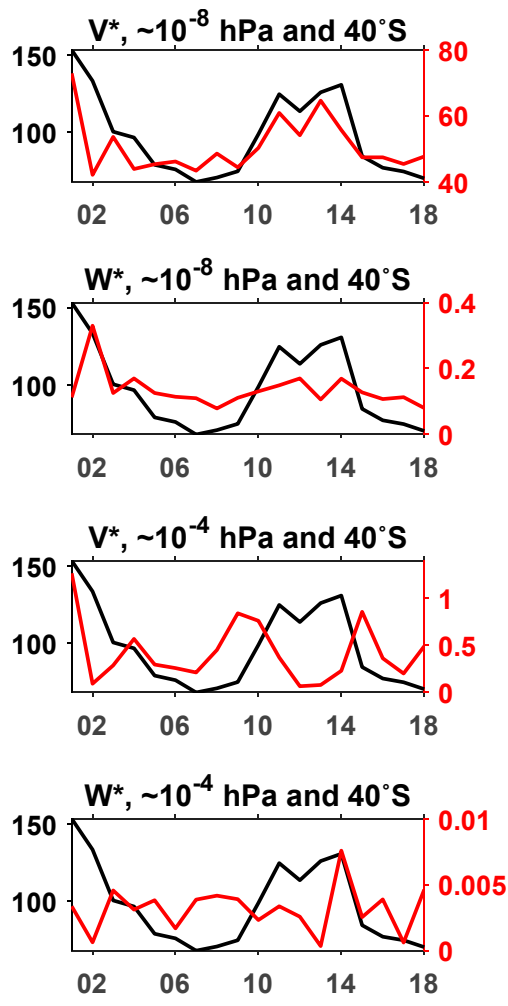

Figure 9. Cont.
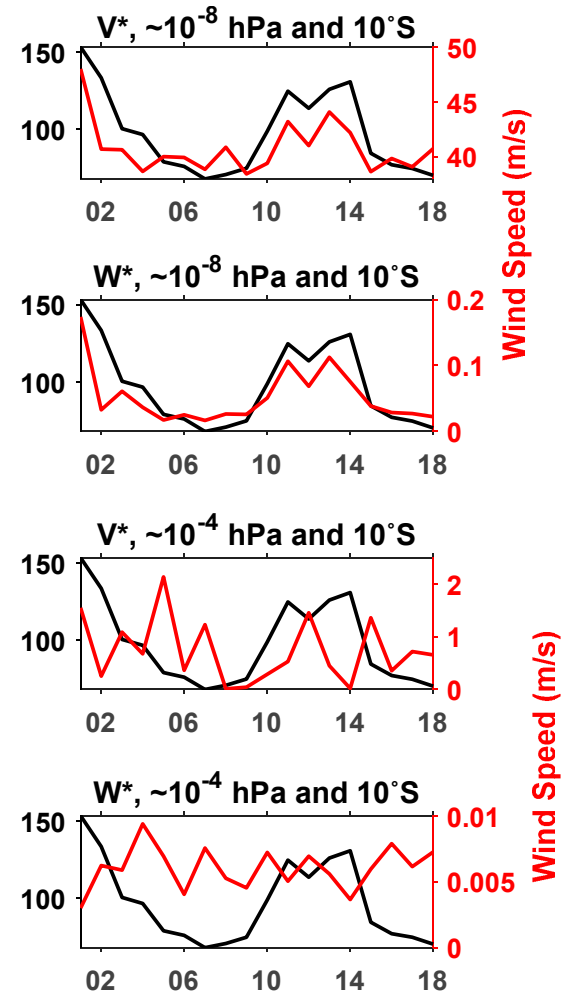

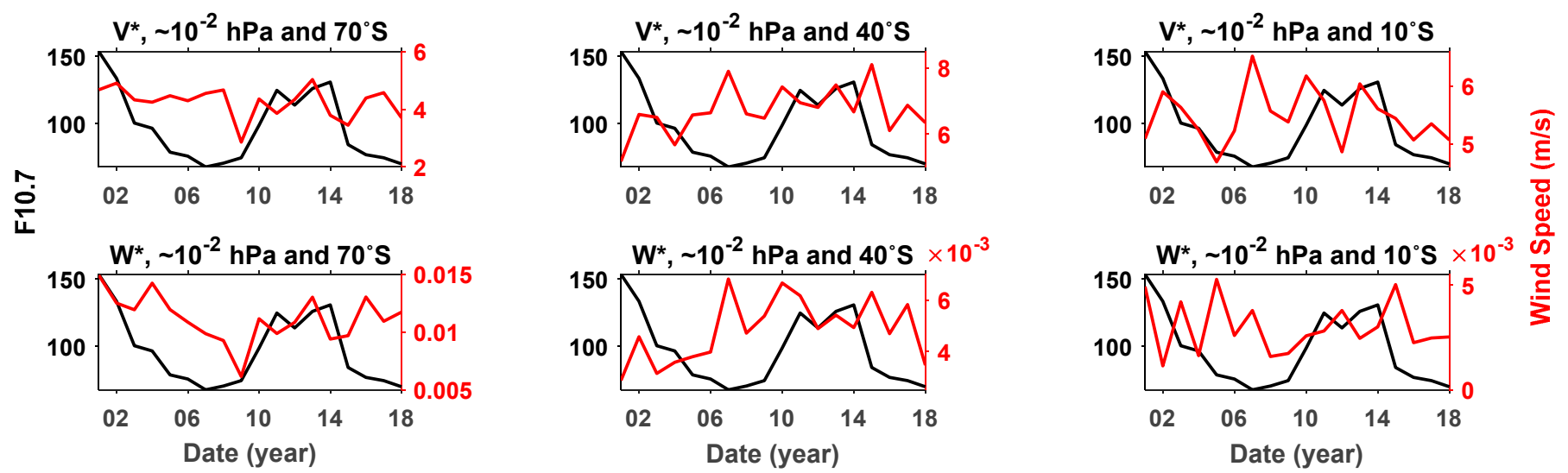

Figure 9. Time series of the meridional and vertical components of atmospheric circulation at a specified altitude $\left(\sim 10^{-8} \mathrm{hPa}\right.$, first two rows; $\sim 10^{-4} \mathrm{hPa}$, middle two rows; $\sim 10^{-2} \mathrm{hPa}$, last two rows $)$ and latitude $\left(\sim 70^{\circ} \mathrm{S}\right.$, left column; 40 $\mathrm{S}$, middle column; $10^{\circ} \mathrm{S}$, right column) and the F10.7 solar index in June from 2002 to 2019 . The black and red lines indicate the F10.7 solar index and the corresponding component of atmospheric circulation, respectively.
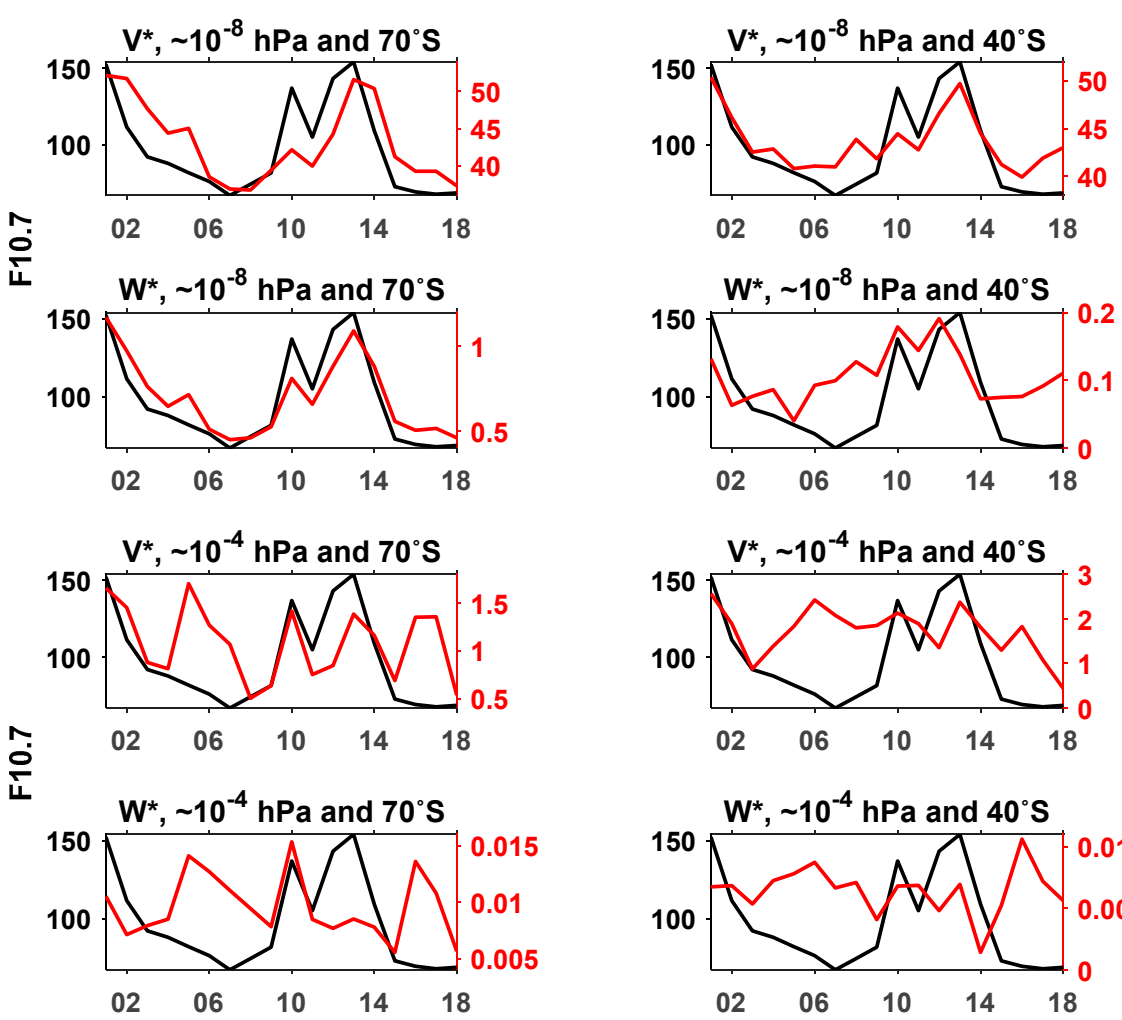
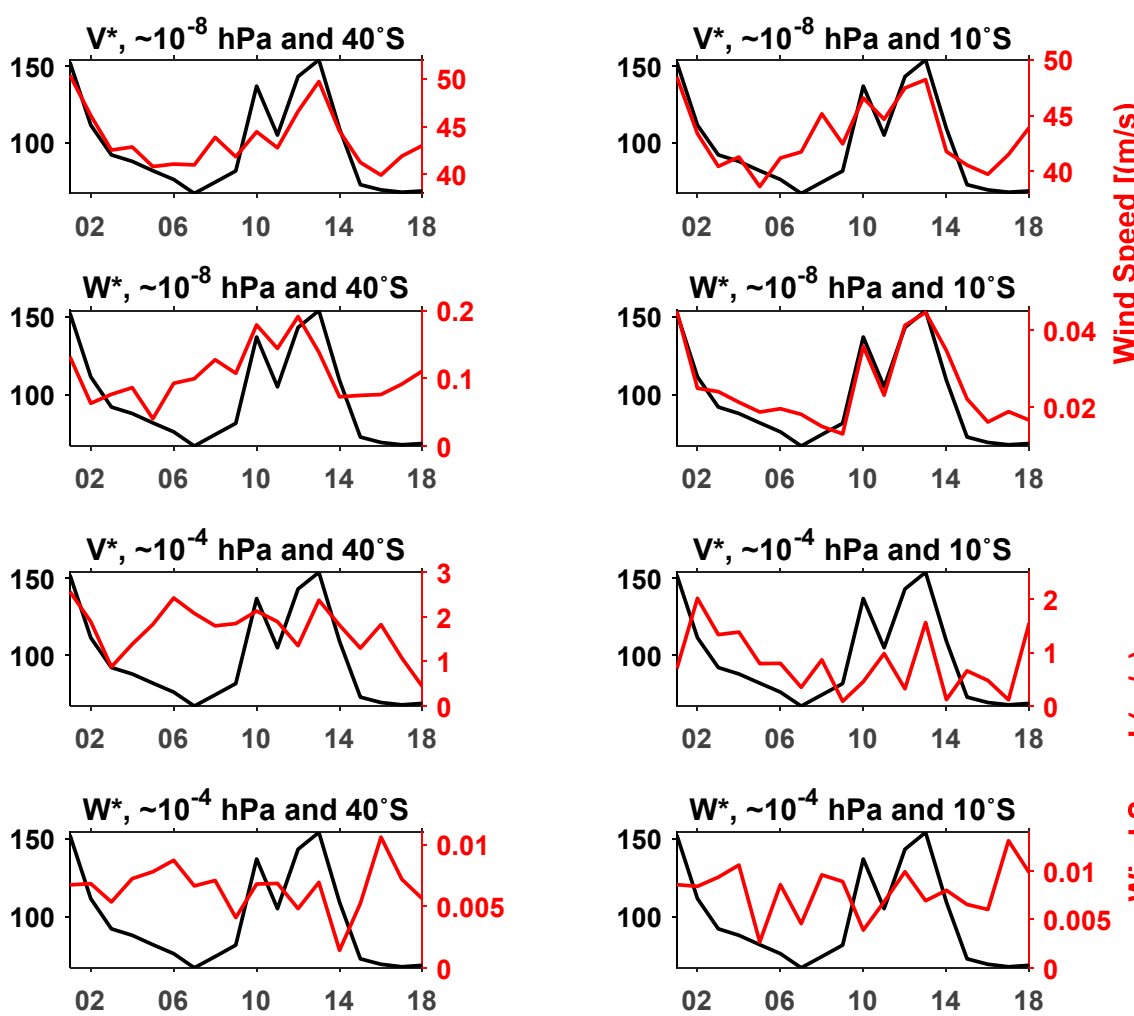

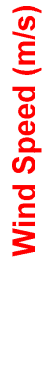

Figure 10. Cont. 

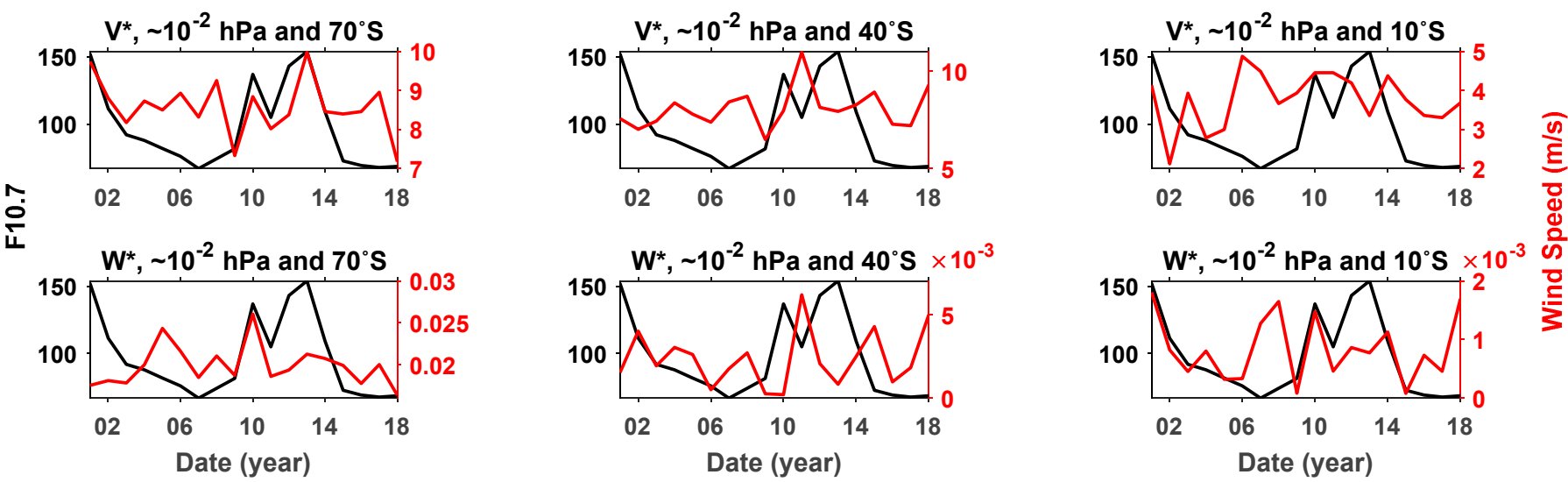

Figure 10. Time series of the meridional and vertical components of atmospheric circulation at a specified altitude $\left(\sim 10^{-8} \mathrm{hPa}\right.$, first two rows; $\sim 10^{-4} \mathrm{hPa}$, middle two rows; $\sim 10^{-2} \mathrm{hPa}$, last two rows $)$ and latitude $\left(\sim 70^{\circ} \mathrm{S}\right.$, left column; $\sim 40^{\circ} \mathrm{S}$, middle column; $\sim 0^{\circ} \mathrm{S}$, right column) and the F10.7 solar index in December from 2002 to 2019. The black and red lines indicate the F10.7 solar index and the corresponding component of atmospheric circulation, respectively.

Table 1. Correlation coefficients of the meridional $\left(\mathrm{V}^{*}\right)$ and vertical $\left(\mathrm{W}^{*}\right)$ components of the atmospheric circulation at a specified altitude and latitude with the F10.7 solar index in June and December from 2002 to 2019.

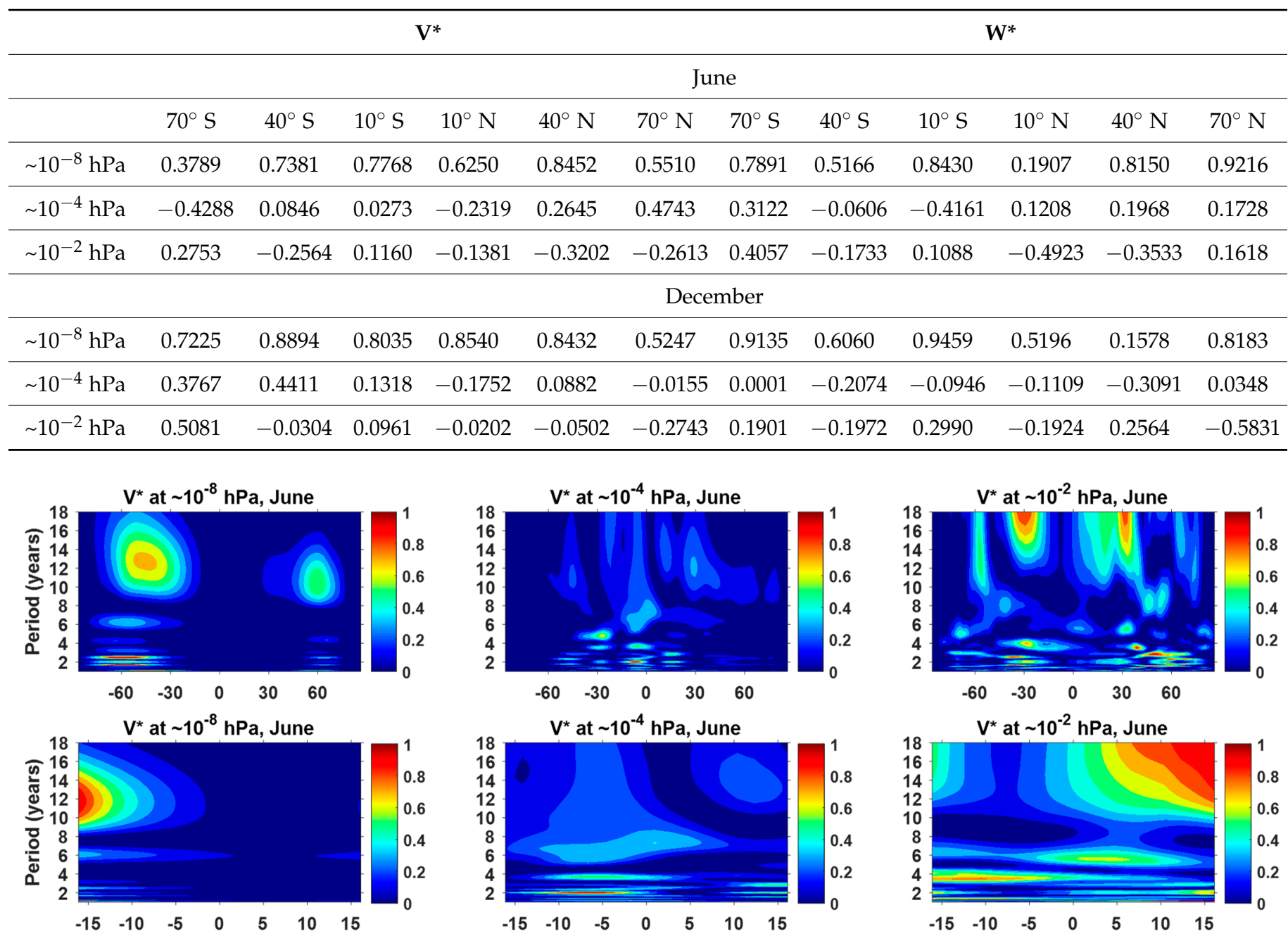

Figure 11. Cont. 

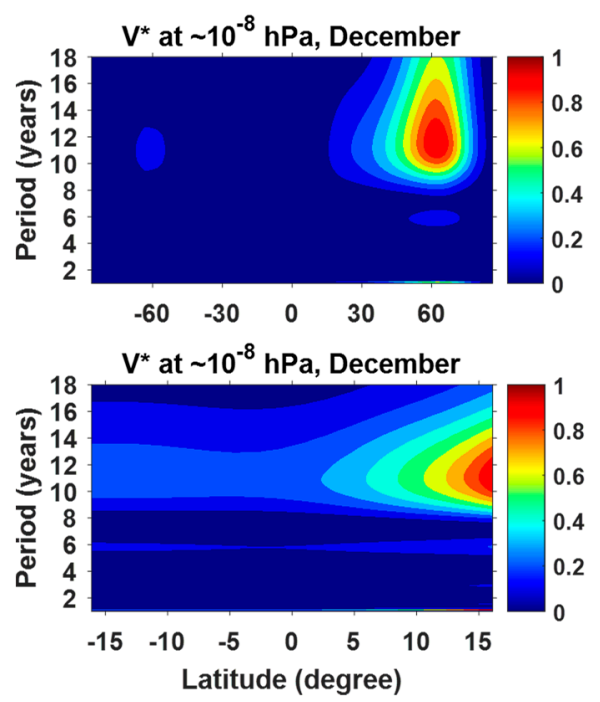
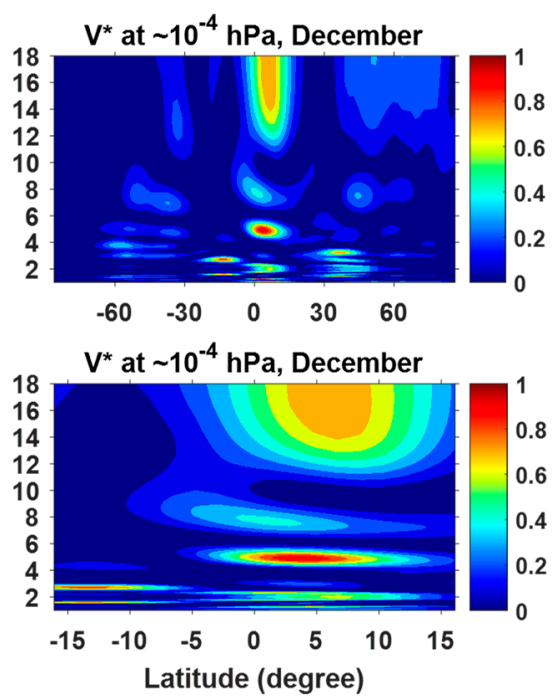
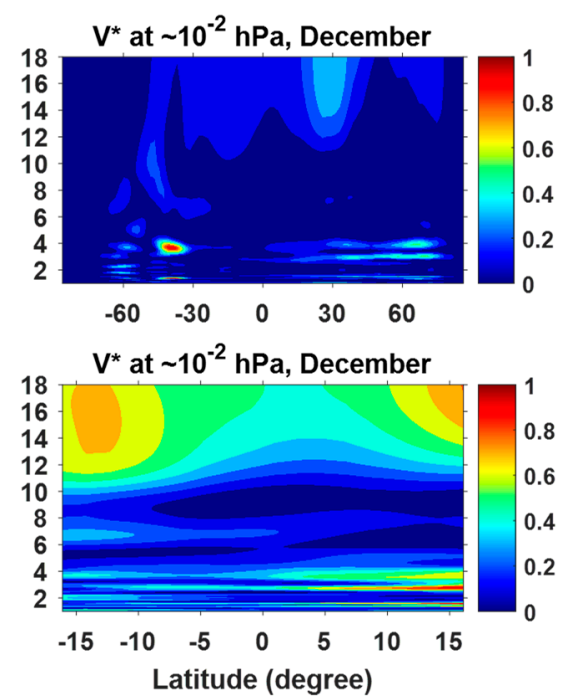

Figure 11. Spectra for the meridional components of atmospheric circulation at $\sim 10^{-8} \mathrm{hPa}$ (left column), $10^{-4} \mathrm{hPa}$ (middle column) and $\sim 10^{-2} \mathrm{hPa}$ (right column) in June (first two rows) and December (last two rows).
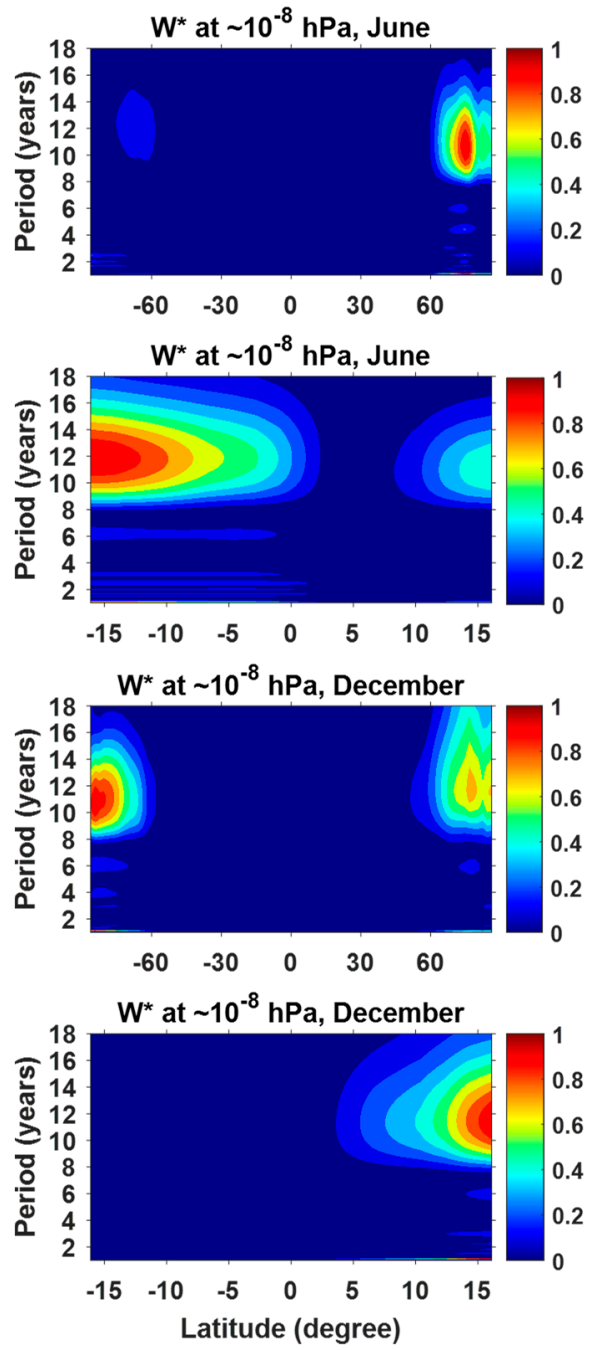

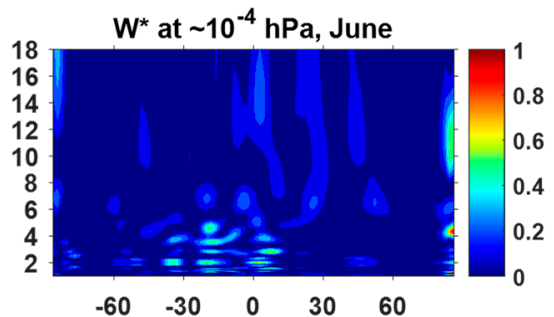

$\mathrm{W}^{\star}$ at $\sim 10^{-4} \mathrm{hPa}$, June
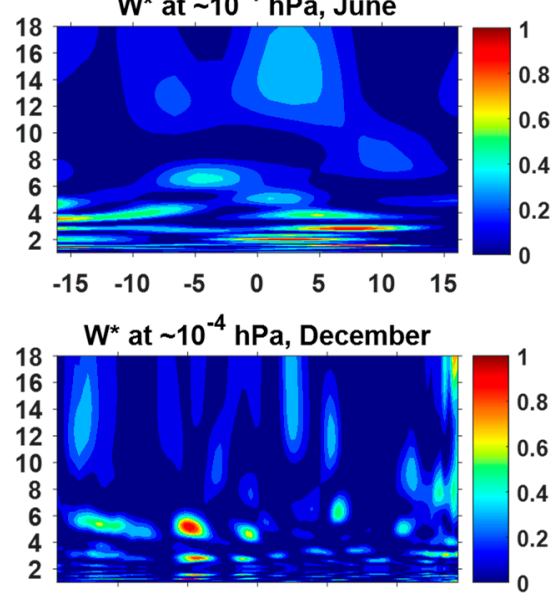

$\begin{array}{lllll}-60 & -30 & 0 & 30 & 60\end{array}$

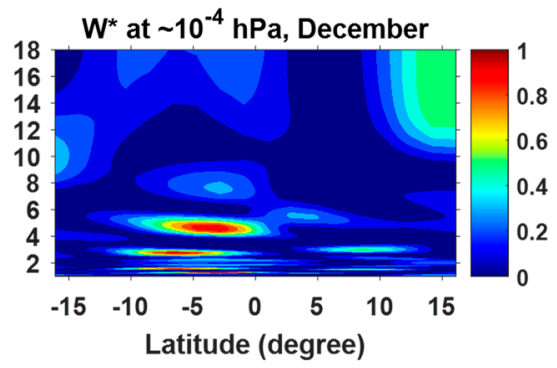

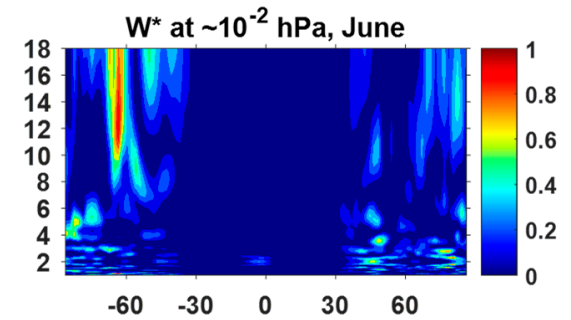
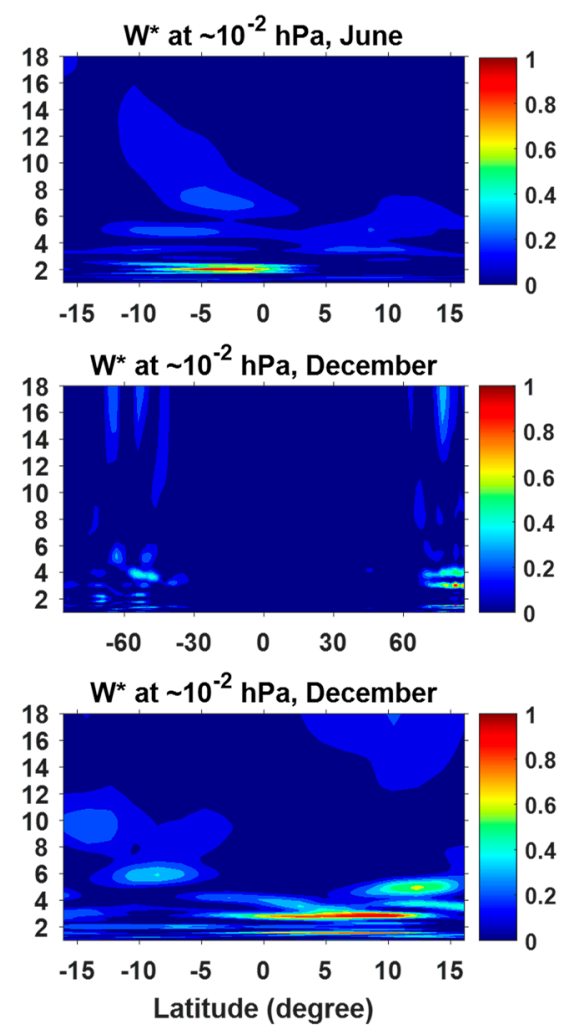

Figure 12. Spectra for the vertical components of atmospheric circulation at $\sim 10^{-8} \mathrm{hPa}$ (left column), $10^{-4} \mathrm{hPa}$ (middle column), and $\sim 10^{-2} \mathrm{hPa}$ (right column) in June (first two rows) and December (last two rows). 


\section{Discussion and Conclusions}

Although many studies have been conducted on the responses of atmospheric circulation to solar activity, they focused on some kinds of atmospheric circulation in the middle and lower atmosphere or at specified latitude regions $[40,41,43,44,46]$. In this work, the responses of global atmospheric circulation from the ground to $\sim 500 \mathrm{~km}$ to solar activity were analyzed. As demonstrated by the results above, solar activity has a significant impact on atmospheric circulation in the upper atmosphere, as high solar activity can enhance the intensity of atmospheric circulation. The atmospheric circulation in the upper atmosphere has an $\sim 11$ year cycle and its temporal variation is highly correlated with the temporal variation in the F10.7 solar index during the same time series, with a correlation coefficient of up to more than 0.9. For different latitudinal regions in the upper atmosphere, solar activity has a stronger impact on the atmospheric circulation in mid- and high-latitude regions than in low-latitude and equatorial regions, which is manifested by a wider variation in the amplitude of atmospheric circulation in mid- and high-latitude regions during different solar activities, as shown in Figures 7e and 8e. However, in the middle and lower atmosphere, atmospheric circulation shows no consistent response to solar activity such as those in the upper atmosphere. In addition, the atmospheric circulation in the middle and lower atmosphere does not have an $~ 11$ year cycle, and its temporal variation has low correlation coefficients with the temporal variation in the F10.7 solar index during the same time series. It is usually accepted that the radiation emitted by the sun is one of the sources of atmospheric circulation [1,60]. During years with high solar activity, increased solar radiation provides more energy to the atmospheric circulation, and magnetospheric energy inputs are increased in polar regions. Thus, atmospheric circulation is enhanced by increased solar energy inputs during years with high solar activity, especially in mid- and high-latitude regions. Increases in greenhouse gases can accelerate atmospheric circulation, and $\mathrm{CO}_{2}$ also exhibits the impacts of the solar cycle $[25,26,28]$. Therefore, the $\sim 11$ year cycle of the atmospheric circulation may be due to changes in $\mathrm{CO}_{2}$. Salinas et al. showed that $\mathrm{CO}_{2}$ decreases during solar maxima throughout the Austral winter mesosphere and lower thermosphere region [45]. This does not lead to enhanced atmospheric circulation in these regions during years with high solar activity. Thus, we thought that the $\sim 11$ year cycle of atmospheric circulation is not due to variations in greenhouse gases; notably, we are not denying the impacts of the changes in greenhouse gases on the variations in atmospheric circulation.

Another question remains: why does this response of atmospheric circulation to solar activity only occur in the upper atmosphere and not in the middle or lower atmosphere? We attribute the phenomenon to the influences of complex atmospheric forcing and processes in the middle and lower atmospheres. Based on previous studies, we know that the ENSO, the QBO, the SSW, volcanic forcing, and atmospheric waves can affect atmospheric circulation $[15,19,21,22,24,44,61]$. These related studies indicate that these atmospheric forcings, processes, and waves mainly influence atmospheric circulation in the middle and lower atmosphere. For instance, these researchers demonstrated that the Brewer-Dobson circulation is significantly enhanced in ENSO winters, and it can be strengthened by the upwelling below the easterly center of the QBO. The SD-WACCM-X used in this work selfgenerates the QBO and the ENSO and provides an expanded database of volcanic sulfate aerosols; it can also simulate atmospheric waves and reproduce SSW events well [48-50,55]. Thus, the simulations in the middle and lower atmosphere are influenced by not only by solar activity but also by these atmospheric forcings, processes, and waves. For example, as shown in Figure 4, the meridional and vertical circulations in the middle and lower atmosphere show obvious stable quasi-biennial variations in low-latitude and equatorial regions. There is a solar $\mathrm{QBO}$, a phenomenon separates from the terrestrial $\mathrm{QBO}$ mentioned in this paper above, and the solar $\mathrm{QBO}$ can be reflected in geophysical disturbances $[62,63]$. The solar QBO has variable periodicity, $0.6-4$ years. In our work, the atmospheric circulation shows a stable quasi-biennial oscillation, aligned with the terrestrial QBO cycle, in the middle and lower atmosphere. Thus, we conclude that this quasi-biennial oscillation of 
atmospheric circulation is mainly due to the terrestrial QBO rather than the solar QBO. Less solar radiation energy is found in the middle and lower atmosphere than in the upper atmosphere, which may result in solar activity having less of an impact on the middle and lower atmosphere. Rao et al. [46] indicated that the Brewer-Dobson circulation in the lower stratosphere intensifies during years with lower solar activity, which does not weaken with the atmospheric circulation in the upper atmosphere. Thus, these research results above indicate that the response of atmospheric circulation in the middle and lower atmosphere to solar activity is not as obvious as in the upper atmosphere. We do not deny that solar activity can affect the atmospheric circulation in the middle and lower atmosphere as reported in the literature.

In conclusion, based on SD-WACCM-X simulations from 2002 to 2019, we investigated the impacts of solar activity on global atmospheric circulation. The results indicate that global atmospheric circulation is enhanced during years with high solar activity, which is particularly noticeable in the upper atmosphere. In the middle and lower atmosphere, additional factors (the QBO, the ENSO, the SSW, volcanic forcing, atmospheric waves and so on) and less solar energy lead to a less pronounced response of the atmospheric circulation to solar activity. The impact of solar activity on atmospheric circulation also has a certain latitudinal distribution: the atmospheric circulation in mid- and high-latitude regions is more affected than in low-latitude and equatorial regions. Thus, when we study some atmospheric responses to the same specific events at different solar activity intensities, we should consider the effect of the differences in atmospheric circulation under different solar activities. At present, limited by the amount of simulations, the full period considered in this work is only about one-and-a-half 11 -year solar cycles. More years of simulations should be added to improve our results and confirm our conclusions in further work.

Author Contributions: Conceptualization, C.-K.-M.T. and S.-Y.G.; software, C.-K.-M.T.; validation, C.-K.-M.T., S.-Y.G. and X.D.; formal analysis, C.-K.-M.T., Y.Q. and S.-Y.G.; investigation, C.-K.-M.T.; resources, S.-Y.G. and X.D.; writing-original draft preparation, C.-K.-M.T.; writing-review and editing, C.-K.-M.T., Y.Q. and S.-Y.G.; funding acquisition, S.-Y.G. and X.D. All authors have read and agreed to the published version of the manuscript.

Funding: This research was funded by the National Natural Science Foundation of China, grant number 41704153, 41874181, and 47341831071.

Institutional Review Board Statement: Not applicable.

Informed Consent Statement: Not applicable.

Data Availability Statement: Not applicable.

Acknowledgments: WACCM-X is an open-source software with source code publicly available at https: / / escomp.github.io/CESM/releasecesm2/downloading_cesm.html\#downloading-the-code-and-scripts, accessed on 18 October 2019. The atmospheric forcing data, which are re-gridded from the MERRA-2 data set and used to run SD-WACCM-X, can be downloaded at https://rda.ucar.edu/datasets/ds313.3/? hash=access, accessed on 18 October 2019. The numerical calculations in this paper were performed on the supercomputing system of the Supercomputing Center of Wuhan University.

Conflicts of Interest: The authors declare no conflict of interest.

\section{References}

1. Pfeffer, R.L. The global atmospheric circulation. Trans. N. Y. Acad. Sci. 1964, 26, 984-997. [CrossRef]

2. Lamb, H.H. Atmospheric Circulation, Climate and Climatic Variations. Geography 1961, 46, 208-222. [CrossRef]

3. Egger, J.; Weickmann, K.; Hoinka, K.P. Angular momentum in the global atmospheric circulation. Rev. Geophys. 2007, 45. [CrossRef]

4. Voigt, A.; Shaw, T.A. Circulation response to warming shaped by radiative changes of clouds and water vapour. Nat. Geosci. 2015, 8, 102-106. [CrossRef]

5. Schneider, T.; Bordoni, S. Eddy-mediated regime transitions in the seasonal cycle of a Hadley circulation and implications for monsoon dynamics. J. Atmos. Sci. 2008, 65, 915-934. [CrossRef]

6. Heikes, R.; Thompson, D.W.J.; Butler, A.H. The Steady-state atmospheric circulation response to climate change-like thermal forcings in a simple general circulation model. J. Clim. 2010, 23, 3474-3496. [CrossRef]

7. Ceppi, P.; Shepherd, T.G. Contributions of climate feedbacks to changes in atmospheric circulation. J. Clim. 2017, 30, 9097-9118. [CrossRef] 
8. Thompson, D.W.J.; Li, Y.; Bony, S. The influence of atmospheric cloud radiative effects on the large-scale atmospheric circulation. J. Clim. 2015, 28, 7263-7278. [CrossRef]

9. Butchart, N. The brewer-dobson circulation. Rev. Geophys. 2014, 52, 157-184. [CrossRef]

10. Maher, P.; Gerber, E.P.; Medeiros, B.; Merlis, T.M.; Sherwood, S.; Sheshadri, A.; Sobel, A.H.; Vallis, G.K.; Voigt, A.; Zurita-Gotor, P. Model hierarchies for understanding atmospheric circulation. Rev. Geophys. 2019, 57, 250-280. [CrossRef]

11. Huth, R.; Beck, C.; Philipp, A.; Demuzere, M.; Ustrnul, Z.; Cahynova, M.; Kysely, J.; Tveito, O.E. Classifications of atmospheric circulation patterns: Recent advances and applications. Ann. N. Y. Acad. Sci. 2008, 1146, 105-152. [CrossRef]

12. Hardiman, S.C.; Butchart, N.; Calvo, N. The morphology of the Brewer-Dobson circulation and its response to climate change in CMIP5 simulations. Q. J. R. Meteorol. Soc. 2014, 140, 1958-1965. [CrossRef]

13. Lupikasza, E.B.; Niedzwiedz, T. The influence of mesoscale atmospheric circulation on spitsbergen air temperature in periods of arctic warming and cooling. J. Geophys. Res.-Atmos. 2019, 124, 5233-5250. [CrossRef]

14. Noguchi, S.; Kuroda, Y.; Kodera, K.; Watanabe, S. Robust enhancement of tropical convective activity by the 2019 antarctic sudden stratospheric warming. Geophys. Res. Lett. 2020, 47, e2020GL088743. [CrossRef]

15. Ruzmaikin, A.; Feynman, J.; Jiang, X.; Yung, Y.L. Extratropical signature of the quasi-biennial oscillation. J. Geophys. Res.-Atmos. 2005, 110. [CrossRef]

16. White, I.P.; Lu, H.; Mitchell, N.J.; Phillips, T. Dynamical response to the QBO in the northern winter stratosphere: Signatures in wave forcing and eddy fluxes of potential vorticity. J. Atmos. Sci. 2015, 72, 4487-4507. [CrossRef]

17. Garfinkel, C.I.; Shaw, T.A.; Hartmann, D.L.; Waugh, D.W. Does the Holton-Tan mechanism explain how the quasi-biennial oscillation modulates the arctic polar vortex? J. Atmos. Sci. 2012, 69, 1713-1733. [CrossRef]

18. Lu, H.; Bracegirdle, T.J.; Phillips, T.; Bushell, A.; Gray, L. Mechanisms for the Holton-Tan relationship and its decadal variation. J. Geophys. Res.-Atmos. 2014, 119, 2811-2830. [CrossRef]

19. Abalos, M.; Legras, B.; Ploeger, F.; Randel, W.J. Evaluating the advective Brewer-Dobson circulation in three reanalyses for the period 1979-2012. J. Geophys. Res.-Atmos. 2015, 120, 7534-7554. [CrossRef]

20. Horel, J.D.; Wallace, J.M. Planetary-Scale atmospheric phenomena associated with the southern oscillation. Mon. Weather Rev. 1981, 109, 813-829. [CrossRef]

21. Calvo, N.; Garcia, R.R.; Randel, W.J.; Marsh, D.R. Dynamical mechanism for the increase in tropical upwelling in the lowermost tropical stratosphere during warm ENSO events. J. Atmos. Sci. 2010, 67, 2331-2340. [CrossRef]

22. Simpson, I.R.; Shepherd, T.G.; Sigmond, M. Dynamics of the lower stratospheric circulation response to ENSO. J. Atmos. Sci. 2011, 68, 2537-2556. [CrossRef]

23. Andrews, D.G.; Holton, J.R.; Leovy, C.B. Middle Atmosphere Dynamics; Academic Press: Orlando, FL, USA, 1987; 489p.

24. Gu, S.; Hou, X.; Qi, J.; TengChen, K.; Dou, X. Reponses of middle atmospheric circulation to the 2009 major sudden stratospheric warming. Earth Planet. Phys. 2020, 4, 1-7. [CrossRef]

25. Garcia, R.R.; Randel, W.J. Acceleration of the Brewer-Dobson circulation due to increases in greenhouse gases. J. Atmos. Sci. 2008, 65, 2731-2739. [CrossRef]

26. Choi, J.; Son, S.W.; Park, R.J. Aerosol versus greenhouse gas impacts on Southern Hemisphere general circulation changes. Clim. Dynam. 2019, 52, 4127-4142. [CrossRef]

27. Roscoe, H.K.; Fowler, C.L.; Shanklin, J.D.; Hill, J.G.T. Possible long-term changes in stratospheric circulation: Evidence from total ozone measurements at the edge of the Antarctic vortex in early winter. Q. J. R. Meteorol. Soc. 2004, 130, 1123-1135. [CrossRef]

28. Brandefelt, J. Atmospheric modes of variability in a changing climate. J. Clim. 2006, 19, 5934-5943. [CrossRef]

29. Tandberg-Hanssen, E. Solar activity. Rev. Geophys. 1973, 11, 469-504. [CrossRef]

30. Liu, L.B.; Wan, W.X.; Ning, B.Q.; Pirog, O.M.; Kurkin, V.I. Solar activity variations of the ionospheric peak electron density. J. Geophys. Res.-Space Phys. 2006, 111. [CrossRef]

31. Fontanari, J.; Alcayde, D.; Bauer, P. Seasonal-changes in thermospheric molecular-oxygen-A Solar-Activity Control. Geophys. Res. Lett. 1982, 9, 551-554. [CrossRef]

32. Kuroda, Y.; Deushi, M.; Shibata, K. Role of solar activity in the troposphere-stratosphere coupling in the Southern Hemisphere winter. Geophys. Res. Lett. 2007, 34. [CrossRef]

33. Martinez-Asensio, A.; Tsimplis, M.N.; Calafat, F.M. Decadal variability of European sea level extremes in relation to the solar activity. Geophys. Res. Lett. 2016, 43, 11744-11750. [CrossRef]

34. Warren, H.P.; Emmert, J.T.; Crump, N.A. Linear forecasting of the $\mathrm{F}_{10.7}$ proxy for solar activity. Space Weather 2017, 15, 1039-1051. [CrossRef]

35. Lean, J.L.; Picone, J.M.; Emmert, J.T. Quantitative forecasting of near-term solar activity and upper atmospheric density. J. Geophys. Res.-Space Phys. 2009, 114. [CrossRef]

36. Kutiev, I.; Tsagouri, I.; Perrone, L.; Pancheva, D.; Mukhtarov, P.; Mikhailov, A.; Lastovicka, J.; Jakowski, N.; Buresova, D.; Blanch, E.; et al. Solar activity impact on the Earth's upper atmosphere. J. Space Weather Space Clim. 2013, 3, A06. [CrossRef]

37. Schmidt, H.; Brasseur, G.P.; Giorgetta, M.A. Solar cycle signal in a general circulation and chemistry model with internally generated quasi-biennial oscillation. J. Geophys. Res.-Atmos. 2010, 115. [CrossRef]

38. Bednarz, E.M.; Maycock, A.C.; Telford, P.J.; Braesicke, P.; Abraham, N.L.; Pyle, J.A. Simulating the atmospheric response to the 11-year solar cycle forcing with the UM-UKCA model: The role of detection method and natural variability. Atmos. Chem. Phys. 2019, 19, 5209-5233. [CrossRef]

39. Wilcox, J.M. Solar-Activity and Changes in Atmospheric Circulation. J. Atmos. Terr. Phys. 1979, 41, 753. [CrossRef] 
40. Kodera, K.; Kuroda, Y. Dynamical response to the solar cycle. J. Geophys. Res.-Atmos. 2002, 107. [CrossRef]

41. Koval, A.V.; Gavrilov, N.M.; Pogoreltsev, A.I.; Shevchuk, N.O. Reactions of the middle atmosphere circulation and stationary planetary waves on the solar activity effects in the thermosphere. J. Geophys. Res.-Space Phys. 2019, 124, 10645-10658. [CrossRef]

42. Vasilyeva, L.A.; Zherebtsov, G.A.; Kovalenko, V.A.; Molodykh, S.I. Peculiarities of long-term variations in the temperature and heat content of the troposphere and their relation to solar activity. Geomagn. Aeron. 2009, 49, 1285-1287. [CrossRef]

43. Sfica, L.; Voiculescu, M.; Huth, R. The influence of solar activity on action centres of atmospheric circulation in North Atlantic. Ann. Geophys. 2015, 33, 207-215. [CrossRef]

44. Karlsson, B.; Kuilman, M. On how the middle atmospheric residual circulation responds to the solar cycle close to the solstices. J. Clim. 2018, 31, 401-421. [CrossRef]

45. Salinas, C.C.J.H.; Chang, L.C.; Liang, M.C.; Qian, L.Y.; Yue, J.; Lee, J.N.; Russell, J.; Mlynczak, M.; Wu, D.L. Solar cycle response of $\mathrm{CO}_{2}$ over the austral winter mesosphere and lower thermosphere region. J. Geophys. Res.-Space Phys. 2018, 123, 7581-7597. [CrossRef]

46. Rao, J.; Yu, Y.Y.; Guo, D.; Shi, C.H.; Chen, D.; Hu, D.Z. Evaluating the Brewer-Dobson circulation and its responses to ENSO, QBO, and the solar cycle in different reanalyses. Earth Planet. Phys. 2019, 3, 166-181. [CrossRef]

47. Meehl, G.A.; Arblaster, J.M.; Matthes, K.; Sassi, F.; van Loon, H. Amplifying the pacific climate system response to a small 11-year solar cycle forcing. Science 2009, 325, 1114-1118. [CrossRef]

48. Mills, M.J.; Schmidt, A.; Easter, R.; Solomon, S.; Kinnison, D.E.; Ghan, S.J.; Neely, R.R.; Marsh, D.R.; Conley, A.; Bardeen, C.G.; et al. Global volcanic aerosol properties derived from emissions, 1990-2014, using CESM1(WACCM). J. Geophys. Res.-Atmos. 2016, 121, 2332-2348. [CrossRef]

49. Ramesh, K.; Smith, A.K. Long-Term variability and tendencies in non-migrating diurnal tide from WACCM6 simulations during 1850-2014. J. Geophys. Res. Space Phys. 2021, 126, e2020JA028904. [CrossRef]

50. Marsh, D.R.; Mills, M.J.; Kinnison, D.E.; Lamarque, J.-F.; Calvo, N.; Polvani, L.M. Climate change from 1850 to 2005 simulated in CESM1(WACCM). J. Clim. 2013, 26, 7372-7391. [CrossRef]

51. Chandran, A.; Collins, R.L. Stratospheric sudden warming effects on winds and temperature in the middle atmosphere at middle and low latitudes: A study using WACCM. Ann. Geophys. 2014, 32, 859-874. [CrossRef]

52. Lean, J.; Rottman, G.; Harder, J.; Kopp, G. SORCE contributions to new understanding of global change and solar variability. Sol. Phys. 2005, 230, 27-53. [CrossRef]

53. Kopp, G.; Lean, J.L. A new, lower value of total solar irradiance: Evidence and climate significance. Geophys. Res. Lett. 2011, 38. [CrossRef]

54. Teng, C.K.M.; Gu, S.Y.; Qin, Y.; Dou, X.; Li, N.; Tang, L. Unexpected decrease in TW3 amplitude during antarctic sudden stratospheric warming events as revealed by SD-WACCM-X. J. Geophys. Res.-Space Phys. 2021, 126. [CrossRef]

55. Qin, Y.; Gu, S.Y.; Teng, C.K.M.; Dou, X.K.; Yu, Y.; Li, N. Comprehensive study of the climatology of the quasi-6-day wave in the MLT region based on Aura/MLS observations and SD-WACCM-X simulations. J. Geophys. Res.-Space Phys. 2020, 126. [CrossRef]

56. Liu, H.L.; Bardeen, C.G.; Foster, B.T.; Lauritzen, P.H.; Liu, J.; Lu, G.; Marsh, D.R.; Maute, A.; McInerney, J.M.; Pedatella, N.M.; et al Development and validation of the whole atmosphere community climate model with thermosphere and ionosphere extension (WACCM-X 2.0). J. Adv. Model. Earth Syst. 2018, 10, 381-402. [CrossRef]

57. Liu, H.L.; Foster, B.T.; Hagan, M.E.; McInerney, J.M.; Maute, A.; Qian, L.; Richmond, A.D.; Roble, R.G.; Solomon, S.C.; Garcia, R.R.; et al. Thermosphere extension of the whole atmosphere community climate model. J. Geophys. Res.-Space Phys. 2010, 115. [CrossRef]

58. Marsh, D.R. Chemical-Dynamical coupling in the mesosphere and lower thermosphere. In Aeronomy of the Earth's Atmosphere and Ionosphere; Abdu, M.A., Pancheva, D., Eds.; Springer: Dordrecht, The Netherlands, 2011; pp. 3-17.

59. Gelaro, R.; McCarty, W.; Suarez, M.J.; Todling, R.; Molod, A.; Takacs, L.; Randles, C.; Darmenov, A.; Bosilovich, M.G.; Reichle, R.; et al. The Modern-Era retrospective analysis for research and applications, version 2 (MERRA-2). J. Clim. 2017, 30, 5419-5454. [CrossRef]

60. Djurovic, D.; Paquet, P. The frequency composition of the madden-julian oscillation-An indication of the solar-activity contribution to the global atmospheric circulation and the earth's rotation. Sol. Phys. 1994, 152, 497-504. [CrossRef]

61. Liu, H.L.; Marsh, D.R.; She, C.Y.; Wu, Q.; Xu, J. Momentum balance and gravity wave forcing in the mesosphere and lower thermosphere. Geophys. Res. Lett. 2009, 36. [CrossRef]

62. Bazilevskaya, G.; Broomhall, A.M.; Elsworth, Y.; Nakariakov, V.M. A combined analysis of the observational aspects of the quasi-biennial oscillation in solar magnetic activity. Space Sci. Rev. 2014, 186, 359-386. [CrossRef]

63. Kane, R.P. Differences in the quasi-biennial oscillation and quasi-triennial oscillation characteristics of the solar, interplanetary, and terrestrial parameters. J. Geophys. Res.-Space Phys. 2005, 110. [CrossRef] 